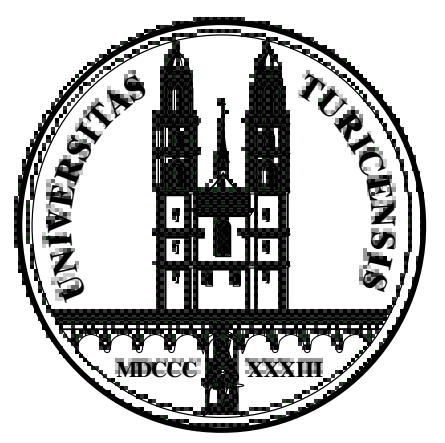

Institute for Empirical Research in Economics

University of Zurich

Working Paper Series

ISSN 1424-0459

Working Paper No. 32

Financial Innovation, Communication and the

Theory of the Firm

Marc Oliver Bettzüge and Thorsten Hens

January 2000 


\title{
Financial Innovation, Communication and the Theory of the Firm
}

\author{
by \\ Marc Oliver Bettzüge and Thorsten Hens ${ }^{1}$ \\ February 2000 \\ Institute for Empirical Economic Research \\ University of Zurich \\ Bluemlisalpstrasse 10 \\ CH-8006 Zurich \\ Switzerland
}

\footnotetext{
${ }^{1}$ M.O. Bettzüge is at McKinsey, Vienna, and at the University of Zurich; Th. Hens is at the University of Zurich. We are grateful for valuable comments by Anke Gerber, for Igor Evstigneev's support on the last part of section 4.2 and for valuable comments of seminar participants at CERMSEM and the SAET conference 1999 held at Rhodes. In particular, we wish to thank David Cass for valuable discussions on the topic. The opinions expressed in this paper do not reflect the opinions of McKinsey and Company, Inc.
} 


\begin{abstract}
When markets are incomplete, the competitive equilibria considered so far are not constrained Pareto-efficient, production efficiency breaks down and shareholders no longer agree on the objective function of the firm.

We first show by way of an example that these inefficiencies originate in the double role of firms in incomplete markets: providing high market value and providing good hedging opportunities (spanning role).

To disentangle these two conflicting roles of the firm's decision, we then suggest to let the firm choose a relevant financial policy by issuing securities being collaterized by the production plan. In order to guarantee that the firm does not choose to innovate trivial assets, it is then shown to be crucial that the firm's shareholders agree on the same set of beliefs. Therefore we introduce some communication network into the model which allows the shareholders to exchange their views on the firm's best policies.

In our main result we demonstrate that competitive equilibria with communication of shareholders and a relevant financial policy of the firm are Paretoefficient, provided there are at least as many firms as there are shareholders.
\end{abstract}

Keywords: theory of the firm, incomplete markets, communication, financial innovation.

J.E.L. Classification Numbers: D21, D52, G32, L21. 


\section{Contents}

1 Introduction $\quad 3$

2 Characteristics of the Economy 5

3 Market structure $\quad 6$

3.1 Complete and Incomplete Markets . . . . . . . . . . . . . . 6

3.2 Partnership Economy . . . . . . . . . . . . . . . . . . 7

3.3 Stock Market Economy . . . . . . . . . . . . . . . . . . 12

4 A new objective function for the firm $\quad 17$

4.1 Relevant financial policy . . . . . . . . . . . . . . . 17

4.2 Communication of beliefs . . . . . . . . . . . . . 21

5 Pareto-efficiency of Stock Market Economies 28

6 Conclusion $\quad 32$

$\begin{array}{ll}\text { References } & 33\end{array}$ 


\section{Introduction}

The integration of productive activity into general equilibrium models has posed a major challenge ever since the work of Walras. The classic Arrow-Debreu-model has provided a solution to this task, provided that markets are complete (see e.g. Debreu(1959)). Subsequently, the Arrow-Debreu-model has been extended to the case of incomplete markets. Surveys of this topic can be found e.g. in Geanakoplos (1990), Magill and Shafer (1991), and Hens (1998). In spite of the success of the incomplete markets model, however, a satisfactory treatment of the theory of the firm in this model has not yet been given. In fact, the approaches to this topic suggested so far imply that most of the standard efficiency properties derived for the general equilibrium model with complete markets are breaking down.

When markets are complete any two commodities (available in possibly different time periods and possibly contingent on certain events) can be compared by their present value. In this case the obvious objective function of the firm is to maximize the present value of its production. As a consequence, competitive equilibria are Pareto-efficient and in particular the production of any one firm cannot be raised without lowering the production of some other firm, i.e. 'production efficiency' holds. Moreover, the firm's production decisions are independent from their shareholders' preferences (i.e. the Fisher-Separation-Principle holds).

In the incomplete markets model, consumers will no longer agree on the present value of those payoffs that cannot be hedged on the existing financial markets. Hence, without further assumptions, the shareholders of a firm will not agree upon the choice of a production plan. Based on some efficiency considerations Drèze (1974) suggested to evaluate a firm's production plan according to the average present value vector of its shareholders, where the weights in averaging are the shares the consumers hold. If consumers are not allowed to trade their shares of the firms, and if there is a single consumption good in each state, this criterion leads to constrained Paretoefficiency, i.e. competitive equilibria cannot be improved upon by a planner who has to use the exogenously given incomplete system of financial markets. Hence although shareholders do not agree about the optimal production plan the Drèze-criterion as the objective function for the firm yields the best efficiency result one could hope for in the presence of incomplete markets. Transferring this criterion to the more general case including trade on stock markets (Drèze (1974) and Grossman and Hart (1979)) the resulting competitive equilibria are no longer constrained Pareto-efficient and shareholders no longer agree that market value maximization should be the unique aim of a firm.

In this paper, we show that these conceptual problems originate in the double role of the firm's production plan when markets are incomplete: providing high market value and providing good hedging opportunities (spanning role of a firm's production decisions). To disentangle these two conflicting roles we suggest to let the firm choose a relevant financial policy by which it issues securities being collateralized by its production plan. The choice of these securities is based on the spanning needs of its shareholders. To be precise, the new securities issued by the firm are chosen according to the average vector of its shareholders' complete markets excess demand, where, 
as usual, the weights in averaging are the shares of the consumers. The production plan is chosen exactly in the same spirit, i.e. firms maximize the average present value of their production. In both decisions, the market value and the spanning decision, following Grossman and Hart (1979), averages are taken according to the initial shares of the consumers.

Note that in contrast to the standard financial policy of the firm (which consists of trading on a given set of financial markets), the financial policy we suggest is not irrelevant in the sense of Modigliani and Miller. Furthermore note that in contrast to some recent literature on financial innovation the security design decision in our model is rather simple. It is directly based on the shareholders' spanning needs and it does not involve any anticipation of the consequences which alternative security designs will have for the shareholders' utility. For approaches of financial innovation relying on anticipation of induced changes in the competitive equilibrium see Duffie and Rahi (1996), Allen and Gale (1994) and Bisin (1998), for example. Furthermore in our model the security design is not based on any additional market imperfections like transaction costs or oligopolistic competition. Such imperfections interfere with the desired efficiency properties of competitive equilibria. The paper closest in spirit to our notion of financial innovation is Citanna and Vilanacci (1996) where an exchange economy is modeled in which every consumer can issue one asset without incuring any costs.

When agents have different beliefs about the state prices, it can occur in this set-up that firms choose to innovate trivial assets, i.e. not to innovate at all. In order to mitigate this effect we model a communication network by which they exchange their beliefs on the profitability of the firms' production plans. As in the choice of the financial policy of the firm we try to keep things simple and model communication by some fixed mechanistic process. According to this communication process, every agent's belief (on the profitability of the firms production plans) is obtained as an average of all those agents' beliefs with whom he communicates. For example, one could suppose that such communication takes place in the assembly of a firm's shareholders. Introducing communication into a general equilibrium model, in which decisions are generally supposed to be taken independently from each other, might be regarded as a surprising step. It becomes more evident, however, when taking a broader perspective on the literature. In game theory, for example, concepts of communication are used to solve coordination problems in normal form games (Matsui (1991)). In our model communication plays a similar coordination role. For some alternative application of communication in financial markets see De Marzo, Vayanos and Zwiebel (1997).

Our main result demonstrates that competitive equilibria with communication among shareholders and a relevant financial policy of firms are Pareto-efficient, provided there are at least as many firms as there are shareholders and provided some regularity conditions are met which rule out degenerated cases both in the communication network as well as in the ownership structure of firms. We show that this result is tight in the sense that without communication or with less firms than shareholders a planner who can anticipate the equilibrium consequences of financial innovations can Pareto-improve the competitive equilibrium by choosing a better financial policy for the firms. 
This paper is organized as follows. Section 2 introduces the general model and notation. Section 3 then presents different forms of market structures for this model. We begin with the well known market structure of contingent contracts and then advance to the case of incomplete markets where we distinguish two cases: the model with and without stock markets. Whereas in the former case we demonstrate constrained Pareto-efficiency, in the latter case we point out why stock market economies are in general constrained Pareto-inefficient. In section 4 we propose our new equilibrium concept with relevant financial policies and communication, and in section 5 we prove that this concept restores Pareto-efficiency. We also show in this section why the introduction of a sufficiently rich communication network is essential to the results obtained. Section 6 concludes and summarizes important open issues remaining.

\section{Characteristics of the Economy}

Let $G E=\left[\mathbb{R}^{n},\left(\mathcal{Y}^{k}\right)_{k=1, \ldots, K},\left(\mathcal{X}^{i}, U^{i}, \omega^{i}, \delta^{i}\right)_{i=1, \ldots, I}\right]$ be a general equilibrium model with

$\mathbb{R}^{n}$ as commodity space,

$\mathcal{Y}^{k} \subset \mathbb{R}^{n}$ being firm k's production set and

$\mathcal{X}^{i}:=\mathbb{R}_{+}^{n}$ being consumer i's consumption set,

$U^{i}: \mathcal{X}^{i} \rightarrow \mathbb{R}$ as consumer i's utility function.

Consumer i's endowments are given as

$\omega^{i} \in \mathcal{X}^{i}$ of commodities and

$\delta^{i} \in[0,1]^{K}$ of shares of firms, where

$\sum_{i} \delta_{k}^{i}=1$, all $k=1, \ldots, K$.

In order to propose our new equilibrium concept we wish to avoid unneccesary technical problems. Therefore, we will assume that GE satisfies strong monotonicity, convexity and differentiability assumptions as for example in Magill and Shafer (1991) who in particular use vectors of firms' endowments $\eta^{k} \in \mathbb{R}^{n}$ in order to perturb the firms' production decisions:

Assumption 1 (Agent characteristics) For every agent $i \in I$ the following assumptions on utility functions and endowments are satisfied: ${ }^{2}$

(1) $U^{i}: \mathbb{R}_{+}^{n} \rightarrow \mathbb{R}$ is continuous on $\mathbb{R}_{+}^{n}$ and infinitely often differentiable on $\mathbb{R}_{++}^{n}$.

(2) If $\mathcal{U}^{i}(\xi):=\left\{x \in \mathbb{R}_{+}^{n} \mid U^{i}(x) \geq U^{i}(\xi)\right\}$ then $\mathcal{U}^{i}(\xi) \subset \mathbb{R}_{++}^{n}, \forall \xi \in \mathbb{R}_{++}^{n}$.

(3) For each $x \in \mathbb{R}_{++}^{n}$, and for all $h \neq 0$ such that $\nabla U^{i}(x) h=0$ it follows that $\nabla U^{i}(x) \in \mathbb{R}_{++}^{n}$ and $h^{T} D^{2} U^{i}(x) h<0$.

(4) $\omega^{i} \in \mathbb{R}_{++}^{n}$.

\footnotetext{
${ }^{2}$ Note that by abuse of notation we will frequently denote cardinalities and index sets by the same letter, i.e. for example $I=\{1, \ldots, I\}$.
} 
Assumption 2 (Firm characteristics) For every firm $k \in K$ the following assumptions on the production set are satisfied:

(1) $\mathcal{Y}^{k} \subset \mathbb{R}^{n}$ is closed, convex and $0 \in \mathcal{Y}^{k}$.

(2) $\mathcal{Y}^{k}$ satisfies free disposal.

(3) The boundary $\partial \mathcal{Y}^{k}$ is a $C^{2}$ manifold with strictly positive Gaussian curvature at each point.

(4) There is a non-empty open set $\mathcal{O} \subset \mathbb{R}^{n(I+K)}$ such that $\sum_{i=1}^{I} \omega^{i}+\sum_{k=1}^{K} \eta^{k} \in \mathbb{R}_{++}^{n}$ and $\left(\sum_{i=1}^{I} \omega^{i}+\sum_{k=1}^{K}\left(\mathcal{Y}^{k}+\eta^{k}\right)\right) \cap \mathbb{R}_{+}^{n}$ is compact for every $(\omega, \eta) \in \Omega:=\mathbb{R}_{++}^{n I} \cap \mathcal{O}$.

\section{Market structure}

\subsection{Complete and Incomplete Markets}

An important characterization of $G E$-economies concerns the availability of markets for the trading of the $n$ commodities. As a major point of reference we therefore recall the well-known case of complete contingent contracts, i.e. the Arrow-Debreumodel. In this model it is assumed that there exists a market for every commodity $l=1, \ldots, n$, and that on each of these markets a price $\pi_{l}, l=1, \ldots, n$, is determined. In this situation, markets are said to be complete. In a competitive equilibrium for such an economy, every agent and every firm takes prices as given, consumers maximize utility, firms maximize market value and all markets clear: ${ }^{3}$

\section{Definition 1}

A competitive equilibrium is an allocation $(\stackrel{*}{x}, \stackrel{*}{y}) \in \mathbb{R}^{n(I+K)}$ and a price system $\stackrel{*}{\pi} \in \mathbb{R}^{n}$ such that

1. $\stackrel{*}{y}^{k} \in \arg \max _{y^{k} \in \mathcal{Y}^{k}} \stackrel{*}{\pi} y^{k}$, for every $k=1, \ldots, K$

2. $\stackrel{*}{x}^{i} \in \arg \max _{x^{i} \in \mathcal{X}^{i}} U^{i}\left(x^{i}\right)$, for every $i=1, \ldots, I$

$$
\text { s.t. } \stackrel{*}{\pi} \cdot x^{i} \leq \stackrel{*}{\pi} \cdot \omega^{i}+\sum_{k=1}^{K} \delta_{k}^{i} \stackrel{*}{\pi} \stackrel{*}{y}^{k}
$$

3. $\sum_{i=1}^{I} \stackrel{*}{x}^{i}=\sum_{i=1}^{I} \omega^{i}+\sum_{k=1}^{K} \stackrel{*}{y}^{k}$.

It is well known that competitive equilibria are Pareto-efficient when markets are complete, i.e. there does not exist an allocation $(\hat{x}, \hat{y})$ that is attainable $\left(\hat{x}^{i} \in \mathcal{X}^{i}, \hat{y}^{k} \in\right.$

\footnotetext{
${ }^{3}$ In order to simplify our notation we use the usual economists' convention that quantities are denoted as column vectors and prices are denoted as row vectors.
} 
$\left.\mathcal{Y}^{k}, \sum_{i} x^{i} \leq \sum_{i} \omega^{i}+\sum_{k} y^{k}\right)$ and satisfies $U^{i}\left(\hat{x}^{i}\right) \geq U^{i}\left(x^{*}\right)$ for all $i=1, \ldots, I$ with one inequality being strict.

On top of leading to Pareto-efficient allocations, competitive equilibria for complete markets display three remarkable and well known features with respect to the firm's production decision: production efficiency, the Fisher-Separation-Principle, and the Modigliani-Miller-Principle. Firstly, when markets are complete, competitive equilibria are production efficient, i.e. the productive output of one commodity can only be increased by lowering the output of another commodity. Secondly, the Fisher-Separation-Principle asserts that the composition of the set of the firm's shareholders is irrelevant for its production decision. When markets are complete this must be true since the availability of prices for every traded commodity makes shareholders unanimously agree on the profit maximal production plan. Finally any financial policy of the firm which consists of trading on a given set of financial markets is irrelevant (Modigliani-Miller-Principle). In fact, by rebalancing her portfolio accordingly, every consumer can "undo" the effects imposed on her by the firm's policy.

In the incomplete markets model, in contrast, agents trade on sequential spot markets which are linked by an incomplete system of financial markets. To simplify the exposition in this paper, we restrict attention to the most basic incomplete markets model with just two time periods $(t=0,1)$, a finite number of states at $t=1$ $(s=1, \ldots, S)$, and just a single, perishable commodity traded on each of the spot markets (i.e. $n=S+1$ ). The single commodity should be thought of as a HicksLeontief composite commodity. In essence this allows us to ignore effects of changes in relative prices among multiple commodities within each state. The efficiency results presented in section 5 (Theorem 3 and Theorem 4) still hold with multiple commodities whereas the efficiency result of section 3.1 (Theorem 2) does depend on ignoring effects of changes in relative prices.

Information is assumed to be symmetric among agents, hence the simple event tree depicted in Figure 1 models the uncertainty faced by every agent. In order to allow agents to transfer wealth between the uncertain states $s=1, \ldots, S$, there are financial assets with payoffs in period $t=1$ which can be traded in the first period spot market. In the partnership economy exposed in section 3.1., only exogenous assets are available for trade. In particular, the shares of the firms, being financial assets in period $t=0$, cannot be traded. In the stock market economy described in section 3.2. both exogenous assets and shares are available for trade.

\subsection{Partnership Economy}

In a partnership economy agents cannot trade their shares of firms. In the first period spot market there are $j=1, \ldots, J$ assets whose payoffs $A^{j} \in \mathbb{R}^{S}$ are denominated in terms of the single commodity. Let $q_{j}, j=1, \ldots, J$ denote the price per unit of asset $\mathrm{j}$ being paid in $t=0$. Given these asset markets, consumers maximize utility 


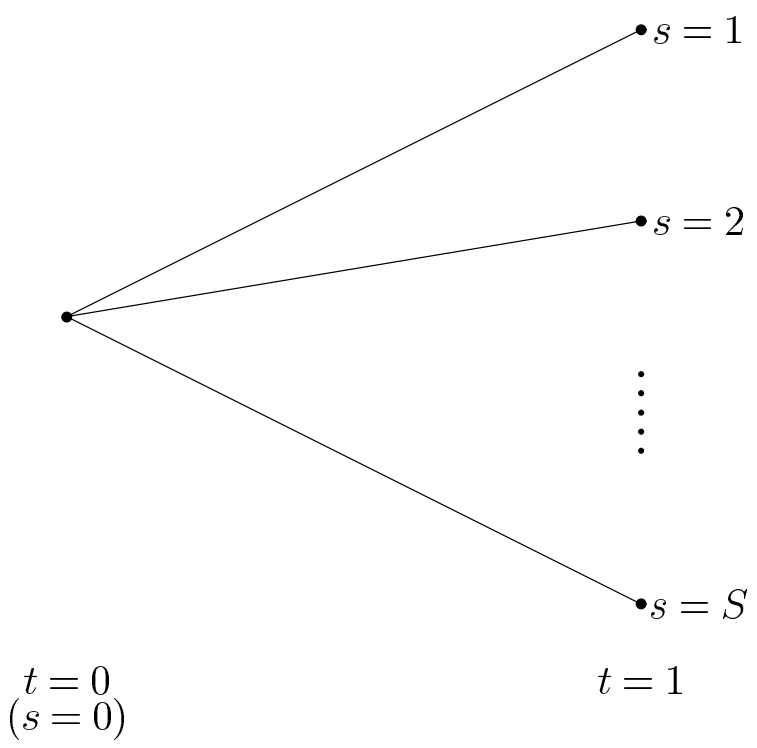

Figure 1: Event Tree for All Agents

and choose portfolios to finance their required net trade vectors:

$$
\begin{gathered}
\stackrel{*}{x}^{i} \in \underset{\substack{x^{i} \in \mathcal{X}^{i} \\
\theta^{i} \in \mathbb{R}^{J}}}{\arg U^{i}\left(x^{i}\right)} \\
\text { s.t. }\left(x^{i}-\omega^{i}-\sum_{k} \delta_{k}^{i} \stackrel{*}{y}^{k}\right)=\left(\begin{array}{c}
-\stackrel{*}{q} \\
A
\end{array}\right) \theta^{i}
\end{gathered}
$$

Due to the monotonicity, convexity and differentiability assumptions made above, a necessary condition for a solution to this maximization problem is

$$
\left(\nabla U^{i}\left(\stackrel{*}{x}^{i}\right)\right) \cdot\left(\begin{array}{c}
-\stackrel{*}{q} \\
A
\end{array}\right)=0, \quad i=1, \ldots, I .
$$

Consumer i's gradient vector $\nabla U^{i}\left({ }^{*} x^{i}\right)$ can be interpreted as the vector of her discount rates for computing the present value of period one payoffs. We normalize utility gradients such that $\left(\nabla U^{i}\left(\stackrel{*}{x}^{i}\right)\right)_{0}=1$, i.e. $\partial_{x_{0}^{i}} U^{i}\left(\stackrel{*}{x}^{i}\right)=1$.

Firms have to choose production plans $y^{k} \in \mathcal{Y}^{k} \subset \mathbb{R}^{S+1}, k=1, \ldots, K$. Hence to obtain an objective function for the firm one has to assign a present value vector $\pi^{k} \in \mathbb{R}^{S+1}$ to each firm. Again, we normalize $\pi_{0}^{k}=1$. For the time being we only assume that this assignment observes the no-arbitrage requirement, i.e. for every firm $k=1, \ldots, K$ we preliminary assign a present value vector $\pi^{k} \in \mathbb{R}_{++}^{S+1}, \pi_{0}^{k}=1$ such that $\left(\pi^{k}\right)\left(\begin{array}{c}-* \\ A\end{array}\right)=0$.

As a further piece of notation, we let $x_{1}:=\left(x_{1}, \ldots, x_{S}\right)$ if $x \in \mathbb{R}^{S+1}$. Then, markets are said to be complete if any period-one net-trading vector

$$
\left(x_{1}^{i}-\omega_{1}^{i}-\sum_{k} \delta_{k}^{i} \stackrel{*}{y}_{1}^{k}\right) \in \mathbb{R}^{S}
$$


can be obtained by asset trade, i.e. if the 'marketed subset', the column span of the payoff matrix, $\langle A\rangle$, coincides with $\mathbb{R}^{S}$. In this case all agents' normalized utility gradients $\nabla U^{i}\left({ }^{*}{ }^{i}\right)$ are identical, and the notion of equilibrium coincides with the point of reference in definition 1 . Otherwise we cannot expect this coincidence. In particular it is well known that for almost all endowments those normalized vectors are pairwise different ( Magill and Quinzii (1996) Theorem 11.6). Hence only in the case of complete markets the present value vector assigned to the firms will naturally coincide with those of the shareholders. ${ }^{4}$

Now we are in a position to state the notion of a competitive equilibrium when markets open sequentially, but firms' shares are not available for trade. Therefore we call this equilibrium concept a Partnership Competitive Equilibrium. Note that the phrase Partnership Equilibrium is used differently by Drèze (1974) and Magill and Quinzii (1996) who consider a model in which consumers can decide on "joining a firm", i.e. on choosing some $\delta_{k}^{i} \geq 0 .{ }^{5}$

\section{Definition Partnership Competitive Equilibrium (FM)}

A tuple $\left(\stackrel{*}{\theta}, \stackrel{*}{x}, \stackrel{*}{y}, \stackrel{*}{q}, \stackrel{*}{\pi}^{k}\right)$ with $\left(\stackrel{*}{\pi}^{k}\right)\left(\begin{array}{c}-\stackrel{*}{q} \\ A\end{array}\right)=0, \quad k=1, \ldots, K$ is a financial markets competitive equilibrium for the partnership economy if

1. $\stackrel{*}{y}^{k} \in \arg \max _{y^{k} \in \mathcal{Y}^{k}} \stackrel{*}{\pi} k^{k} y^{k} \quad$ for every $k=1, \ldots, K$

2. $\left(\stackrel{*}{x}^{i}, \stackrel{*}{\theta}^{i}\right) \in \underset{\substack{x^{i} \in \mathcal{X}^{i} \\ \theta^{i} \in \mathbf{R}^{J}}}{\arg \max } U^{i}\left(x^{i}\right) \quad$ for every $i=1, \ldots, I$

$$
\text { s.t. }\left(x^{i}-\omega^{i}-\sum_{k} \delta_{k}^{i} y^{k}\right)=\left(\begin{array}{c}
* \\
A
\end{array}\right) \theta^{i}
$$

3. $\sum_{i=1}^{I} \stackrel{*}{x}{ }^{i}=\sum_{i=1}^{I} \omega^{i}+\sum_{k=1}^{K} \stackrel{*}{y^{k}}$

4. $\sum_{i=1}^{I} \stackrel{*}{\theta}^{i}=0$.

Using the no-arbitrage condition one can rewrite the consumer's decision problem in the following way:

$$
\begin{array}{ll}
2^{\prime} . & { }^{*} x^{i} \in \arg \max _{x^{i} \in \mathcal{X}^{i}} U^{i}\left(x^{i}\right) \\
& { }^{*} i \cdot\left(x^{i}-\omega^{i}-\sum_{k} \delta_{k}^{i} \stackrel{*}{*}^{k}\right)=0 \\
& \left(x_{1}^{i}-\omega_{1}^{i}-\sum_{k} \delta_{k}^{i} y_{1}^{*}\right) \in<A>.
\end{array}
$$

\footnotetext{
${ }^{4}$ Note that the solution to the system of equations $\pi\left(\begin{array}{c}-q \\ A\end{array}\right)=0, \pi_{0}=1, \pi \gg 0$, is of dimension $S-\operatorname{rg}(A)$, so that state prices compatible with asset prices are indeterminate unless $\operatorname{rg}(A)=S$.

${ }^{5}$ In this case one has to assume that firms have constant returns to scale production technologies.
} 
In 2 '. we can normalize state price vectors $\stackrel{*}{*}^{i}$ such that $\stackrel{*}{\pi}_{0}^{i}=1$. The competitive equilibrium defined above in its so called 'financial market version' (FM) can then equivalently be defined in the following 'no-arbitrage version' (NA).

\section{Definition Partnership Competitive Equilibrium (NA)}

$A$ tuple $(\stackrel{*}{x}, \stackrel{*}{y})$ and a vector $\stackrel{*}{\pi}^{d} \in \mathbb{R}_{++}^{S+1}$ with $\stackrel{*}{\pi}_{0}^{d}=1$, and $A^{T}\left(*_{1}^{*}{ }_{1}^{d} \stackrel{*}{\pi}_{1}^{d^{\prime}}\right)=0$, for all $d, d^{\prime} \in\{1, \ldots, I\} \cup\{1, \ldots, K\}^{6}$ is a no-arbitrage competitve equilibrium for the partnership economy if

$$
\begin{aligned}
& \text { 1. } \stackrel{*}{y}^{k} \in \underset{y^{k} \in \mathcal{Y}^{k}}{\arg \max } \stackrel{*}{\pi}^{k} y^{k}, \quad \text { for every } k=1, \ldots, K \\
& \text { 2. } \stackrel{*}{x}^{i} \in \underset{x^{i} \in \mathcal{X}^{i}}{\arg \max } U^{i}\left(x^{i}\right), \quad \text { for every } i=1, \ldots, I \\
& \text { s.t. } \stackrel{*}{*}^{i} \cdot\left(x^{i}-\omega^{i}-\sum_{k} \delta_{k}^{i} \stackrel{*}{y}^{k}\right)=0 \\
& \text { and }\left(x_{1}^{i}-\omega_{1}^{i}-\sum_{k} \delta_{k}^{i} \stackrel{*}{y}_{1}^{k}\right) \in<A> \\
& \text { 3. } \sum_{i=1}^{I} \stackrel{*}{x}^{i}=\sum_{i=1}^{I} \omega^{i}+\sum_{k=1}^{K} \stackrel{*}{y}^{k}
\end{aligned}
$$

In constrast to the case of complete markets mentioned above, the competitive equilibria for partenrship economies just defined do not satisfy production efficiency and the Fisher-Separation-Principle as long as markets are incomplete (i.e. $\operatorname{rg}(A)<S$ ). In fact, since now firms maximize with respect to possibly different state price vectors, $\pi^{*}$, production efficiency can no longer be expected. Also, since the firm's present value vector can be distinct from that of its shareholders, the production plan chosen by the firm can be different to the production plan which any shareholder would prefer. Hence the Fisher-Separation-Principle fails to hold. The Modigliani-MillerPrinciple, however, is still valid in this economy even if markets are incomplete. For a precise statement and proof of the Modigliani-Miller-Theorem when markets open sequentially see De Marzo (1988).

It is important to note that the competitive equilibria (FM) and (NA) are not well determinate. In a competitive equilibrium (FM) or (NA) the consumer's optimal consumption $\stackrel{*}{x}^{i}$ is not affected by altering the choice of state prices ${ }^{*} i$ satisfying $\left(\stackrel{*}{\pi}^{i}\right)\left(\begin{array}{c}-* \\ A\end{array}\right)=0$. This is true because state prices compatible with the no-arbitrage condition only differ on $\langle A\rangle^{\perp}$, while consumers' net trade vectors must lie in $<A>$ by the spanning constraint. The same argument, however, does not apply to the firms and their optimal production plans, because $y^{k}$ does not need to be in $<A>$ for $k \in K$. As a result, the indeterminacy in state prices translates into an

\footnotetext{
${ }^{6}$ This shorthand notation is used to indicate every pair $d, d^{\prime}$ consisting of either two firms, two individuals or one firm and one individual.
} 
indeterminacy of allocations $(\stackrel{*}{x}, \stackrel{*}{y})$ in competitive equilibria with incomplete markets (Duffie and Shafer (1988)).

To avoid this real indeterminacy, the objective function of the firm, i.e. the firm's state price vector $*^{*}$, should not be assigned arbitrarily but rather be determined by the economy itself. The firm should make decisions which are supported by its shareholders, because, as a matter of fact, it is the assembly of shareholders which decides on the firm's policy. Among other criteria, as for example majority voting (De Marzo (1993)), the following objective function of the firm is most commonly suggested for partnership economies:

$$
\pi^{k}=\sum_{i=1}^{I} \delta_{k}^{i} \nabla U^{i}\left(x^{i}\right)
$$

According to this criterion the firm should use the average of the consumers' (normalized) present value vectors, where the weights for averaging are the shares of the consumers. We will call this criterion the Grossman and Hart-criterion.

It is remarkable that the Grossman-Hart-criterion works perfectly well for partnership economies with a single consumption good in each state: It guarantees constrained Pareto-efficiency which is the most one can hope for when financial markets are incomplete and are exogenously given. In the notion of constrained Paretoefficiency one compares the equilibrium allocations with alternative allocations that are attainable given the incomplete set of markets.

\section{Definition Constrained Attainability (Partnership Economy)}

An allocation $(x, y) \in \mathbb{R}_{+}^{(S+1) \times I} \times \prod_{k=1}^{K} \mathcal{Y}^{k}$ is constrained attainable, if $\sum_{i=1}^{I} x^{i}=\sum_{i=1}^{I} \omega^{i}+$ $\sum_{k=1}^{K} y^{k}$ and $\left(x_{1}^{i}-\omega_{1}^{i}-\sum_{k} \delta_{k}^{i} y_{1}^{k}\right) \in<A>$ for every $i=1, \ldots, I$.

\section{Definition Constrained Pareto-efficiency}

An allocation $(x, y)$ is constrained Pareto-efficient if there does not exist an alternative constrained attainable allocation $(\hat{x}, \hat{y})$ that satisfies $U^{i}\left(\hat{x}^{i}\right) \geq U^{i}\left(x^{i}\right), i=1, \ldots, I$ with at least one inequality being strict.

As the next theorem shows, this weaker notion of Pareto-efficiency is satisfied by competitive equilibria of partnership economies.

\section{Theorem 2}

Partnership competitive equilibria based on the Grossman-Hart-criterion are constrained Pareto-efficient.

\section{Proof:}

Let $(\stackrel{*}{x}, \stackrel{*}{y})$ be a competitive equilibrium allocation. Suppose there exists a constrained attainable allocation $(\hat{x}, \hat{y})$ such that $U^{i}\left(\hat{x}^{i}\right) \geq U^{i}\left(\stackrel{*}{x}^{i}\right), i=1, \ldots, I$ with one inequal- 
ity being strict. By the concavity of $U^{i}$, this implies that $\nabla U^{i}\left({ }^{*} x^{i}\right) \cdot\left(\hat{x}^{i}-\stackrel{*}{x}^{i}\right) \geq 0, i=$ $1, \ldots, I$ with one inequality being strict.

Now let $\left(\hat{x}^{i}-\stackrel{*}{x}^{i}\right)=\sum_{k} \delta_{k}^{i}\left(\hat{y}^{k}-\stackrel{*}{y}^{k}\right)+\tau^{i}$. Then $\tau_{1}^{i} \in<A>$ for every $i=1, \ldots, I$ since by assumption $\left(\hat{x}_{1}^{i}-\omega_{1}^{i}+\sum_{k} \delta_{k}^{i} \hat{y}_{1}^{k}\right)$ and $\left(\hat{x}_{1}^{*}-\omega_{1}^{i}+\sum_{k} \delta_{k}^{i}{ }_{y}^{*}\right)$ are in $\langle A>$. Hence

$$
\sum_{i} \nabla U^{i}\left(*^{i}\right)\left(\hat{x}^{i}-\stackrel{*}{x}^{i}\right)=\sum_{k} \sum_{i} \nabla U^{i}\left(*^{i}\right)\left(\delta_{k}^{i}\left(\hat{y}^{k}-\stackrel{*}{y}^{k}\right)+\tau^{i}\right)
$$

Note that $\sum_{i} \tau_{0}^{i}=0$ by attainability of $(\stackrel{*}{x}, \stackrel{*}{y})$ and of $(\hat{x}, \hat{y})$. Moreover, since $\tau_{1}^{i} \in\langle A\rangle$ we get

$$
\sum_{i} \nabla U^{i}\left(*^{*} i\right)\left(\hat{x}^{i}-\stackrel{*}{x}^{i}\right)=\sum_{k} \sum_{i}\left(\delta_{k}^{i} \nabla U^{i}\left(*^{*}\right)\right)\left(\hat{y}^{k}-\stackrel{*}{y}^{k}\right)>0
$$

contradicting firms' profit maximization, i.e. part 1. of the definition of a competitive equilibrium.

Note in passing that constrained Pareto-efficiency does not necessarily imply production efficiency. Even if production could be organized more efficiently, due to the incompleteness of markets it is not necessarily possible to redistribute the gains in production to the consumers. Also note that in contrast to the Fisher-SeparationPrinciple constrained Pareto-efficiency does not require unanimity of shareholders! The Grossman-Hart-criterion is an efficient way of mitigating different opinions of shareholders, and the principle of market value maximization is the correct criterion to be followed in a partnership economy!

\subsection{Stock Market Economy}

In addition to the existence of (exogenous) asset markets, we now consider an economy, where agents can also trade their shares in the firms on competitive stock markets. These stock markets also open in the first period of the two-periods model. Let $r^{k}$ denote the sum of the k-th firm's stock market price and its first period investment $y_{0}^{k}, k=1, \ldots, K$. Then the matrix determining the possible income transfers can be written as $\left[\begin{array}{cc}-q & -r \\ A & Y_{1}\end{array}\right]$, where we have defined, by slightly abusing notation, $Y:=\left(y^{1}, \ldots, y^{K}\right)$, and, similar to the corresponding vector notation, $Y_{1}:=\left(y_{1}^{1}, \ldots, y_{1}^{K}\right)$. The no-arbitrage condition now has to hold for this enlarged matrix. Note that consumer i's portfolio, $\theta^{i}$, now consists of shares of the exogenous assets and consumer i's net trade in the shares of the firms.

It is straightforward to extend the notion of a competitive equilibrium to this situation. 


\section{Definition Stock Market Competitive Equilibrium (FM)}

A set of vectors $\left(\stackrel{*}{\theta}, \stackrel{*}{x}, \stackrel{*}{y}, \stackrel{*}{q}, \stackrel{*}{r}, \stackrel{*}{*}^{k}\right)$ with $\stackrel{*}{\pi} k\left[\begin{array}{cc}* & -\stackrel{*}{r} \\ A & \stackrel{*}{Y}_{1}\end{array}\right]=0$, for every $k=1, \ldots, K$ is a financial markets competitive equilibrium for a stock market economy if

1. $\stackrel{*}{y}^{k} \in \underset{y^{k} \in \mathcal{Y}^{k}}{\arg \max } \stackrel{*}{\pi}^{k} y^{k}$ for every $k=1, \ldots, K$

2. $\left(\stackrel{*}{\theta}^{i}, \stackrel{*}{x}^{i}\right) \in \underset{x^{i} \in \mathcal{X}^{i}, \theta^{i} \in \mathbb{R}^{J+K}}{\arg \max } U^{i}\left(x^{i}\right)$ for every $i=1, \ldots, I$

s.t. $\left(x^{i}-\omega^{i}-\sum_{k} \delta_{k}^{i} \stackrel{*}{y} k\right)=\left[\begin{array}{cc}-\stackrel{*}{q} & -\stackrel{*}{r} \\ A & \stackrel{*}{Y}\end{array}\right] \theta^{i}$

3. $\sum_{i} \stackrel{*}{x}^{i}=\sum_{i} \omega^{i}+\sum_{k} \stackrel{*}{k}^{k}$

4. $\sum_{i} \stackrel{*}{\theta}^{i}=0$

This (FM)-definition is equivalent to:

Definition Stock Market Competitive Equilibrium (NA) A set of vectors $(\stackrel{*}{x}, \stackrel{*}{y}, \stackrel{*}{\pi})$ with $\stackrel{*}{\pi} \in \mathbb{R}_{++}^{S+1}$ with $\stackrel{*}{*}_{0}^{d}=1$ and $\left(*_{0}^{d}-*_{\pi}^{d^{\prime}}\right)\left[A, \stackrel{*}{Y}_{1}\right]=0$ for all $d, d^{\prime} \in$ $\{1, \ldots, I\} \cup\{1, \ldots, K\}$ is a no-arbitrage competitive equilibrium for a stock market economy if

1. $\stackrel{*}{y}^{k} \in \underset{y^{k} \in \mathcal{Y}^{k}}{\arg \max } \stackrel{*}{\pi} k^{k}$ for every $k=1, \ldots, K$

2. $\stackrel{*}{x}^{i} \in \underset{x^{i} \in \mathcal{X}^{i}}{\arg \max } U^{i}\left(x^{i}\right)$ for every $i=1, \ldots, I$

s.t. $\stackrel{*}{\pi}^{i} \cdot\left(x^{i}-\omega^{i}-\sum_{k} \delta_{k}^{i} \stackrel{*}{y}^{k}\right)=0$

and $\left(x_{1}^{i}-\omega_{1}^{i}-\sum_{k} \delta_{k}^{i} \stackrel{*}{y}{ }_{1}^{k}\right) \in<A, \stackrel{*}{Y_{1}}>$

3. $\sum_{i} \stackrel{*}{x}^{i}=\sum_{i} \omega^{i}+\sum_{k} \stackrel{*}{y}^{k}$

Similarly, the notion of constrained Pareto-efficiency introduced in the previous section can also be extended. The only difference to the case of a partnership economy consists in a slightly different notion of attainability. 
Definition Constrained Attainability (Stock Market Economy) An allocation $(x, y) \in \mathbb{R}^{(S+1) \times I} \times \prod_{k=1}^{K} \mathcal{Y}^{k}$ is constrained attainable, if $\sum_{i=1}^{I} x^{i}=\sum_{i=1}^{I} \omega^{i}+\sum_{k=1}^{K} y^{k}$ and $\left(x_{1}^{i}-\omega_{1}^{i}-\sum_{k}\left(\delta_{k}^{i}+\theta_{k}^{i}\right) y_{1}^{k}\right) \in<A, Y_{1}>$ for every $i=1, \ldots, I$.

Note that the shares of firms are relevant as financial assets only if $\left\langle Y_{1}\right\rangle$ is not included in $\langle A\rangle$, i.e. if these additional financial markets allow the agents to better finance their net trade on commodity markets. In particular, note that when asset markets are complete, i.e. when $\langle A\rangle=\mathbb{R}^{S}$, then there is no reason to trade on stock markets! When markets are incomplete, however, the choice of the production plan can have two effects on the consumers' budget set. As in the complete markets case the firm's market value $\stackrel{*}{\pi}^{*} \stackrel{*}{k}^{k}$ is part of the consumer's disposable income but in contrast to the complete markets case the choice of the production plan affects the spanning opportunities $\left\langle A, \stackrel{*}{Y}{ }_{1}\right\rangle$.

This double role of the production plans now implies that competitive equilibria of stock market economies no longer need to be constrained Pareto-efficient. Although the production plans in such equilibria still are profit maximal (part 1 of the definition) they might not be chosen such as to offer the optimal span of traded assets. In fact, since shares are traded assets, a benevolent planner now can freely determine up to $K$ dimensions of the subspace of traded assets. As the following example demonstrates, his choice for the traded subset will generally not coincide with the one chosen by the notion of competitive equilibrium. This, of course, implies that we cannot expect competitive equilibria of a stock market economy to be constrained Pareto-efficient.

\section{Example $1^{7}$}

There are two states, $S=2$, two consumers, $I=2$, and one firm, $K=1$. Each consumer is endowed with one unit of the commodity in the first period and consumer 1 (2) has one unit of the commodity in state 1 (2), i.e. $\omega^{1}=(1,1,0), \omega^{2}=(1,0,1)$. Both consumers hold equal shares of the firm, i.e. $\delta^{1}=\delta^{2}=\frac{1}{2}$. Consumers do not value first period consumption and they evaluate second period consumption according to some expected utility function with the same objective probabilities $U^{i}\left(x_{0}^{i}, x_{1}^{i}, x_{2}^{i}\right)=$ $u^{i}\left(x_{1}^{i}\right)+u^{i}\left(x_{2}^{i}\right)$ for $i=1,2$. On investing both units of the commodity available in the first period the firm can produce second-period output given by

$$
\mathcal{Y}_{1}(\varepsilon)=\left\{\left(y_{1}, y_{2}\right) \mid y_{1}^{2}+y_{2}^{2} \leq 2 \varepsilon^{2}\right\}
$$

where we have fixed $y_{0}=-2$. Figure 2 displays the second-period production possibility frontier as well as the corresponding Edgeworth-Box. When asset markets are complete, i.e. when $\langle A\rangle=\mathbb{R}^{2}$, then the Pareto-efficient competitive equilibrium

\footnotetext{
'Note that the agents' characteristics given in example 1 do not exactly satisfy the strong differentiability assumptions made in the presentation of the economy (utility of the agents does not vary with first period consumption, utilities are not defined on the boundary of the consumption sets, and the resources are not strictly positive). However, slightly perturbing the vector of resources and the utility functions would restore Assumption 1 without changing the results of Example 1.
} 
allocation is

$$
\stackrel{*}{x}^{1}=\stackrel{*}{x}^{2}=\frac{1}{2}\left(\begin{array}{c}
0 \\
1+\varepsilon \\
1+\varepsilon
\end{array}\right), \stackrel{*}{y}=\left(\begin{array}{c}
-2 \\
\varepsilon \\
\varepsilon
\end{array}\right) .
$$

Now suppose however, that markets are seriously incomplete because $\langle A\rangle=\{0\}$. The firm's production plan, which is supposed to maximize its market value according to some strictly positive state prices, is strictly positive in the second period, i.e. $\stackrel{*}{y}_{1}(\varepsilon) \gg 0$. As an effect, the second-period components of the incomplete markets budget set collapse to the points $\omega_{1}^{i}+\frac{1}{2}<\ddot{y}_{1}>$ for $i=1,2$. Hence when markets are incomplete there is no opportunity to trade and the equilibrium allocation is

$$
\stackrel{*}{x}^{1}=\left(\begin{array}{l}
0 \\
1 \\
0
\end{array}\right)+\frac{1}{2}\left(\begin{array}{c}
0 \\
\stackrel{*}{y}_{1}(\varepsilon) \\
\stackrel{*}{y}_{2}(\varepsilon)
\end{array}\right), \quad \stackrel{*}{x}^{2}=\left(\begin{array}{l}
0 \\
0 \\
1
\end{array}\right)+\frac{1}{2}\left(\begin{array}{c}
0 \\
\stackrel{*}{y}_{1}(\varepsilon) \\
\ddot{*}_{2}(\varepsilon)
\end{array}\right) .
$$

Note that in both states $s=1,2$ the optimal output $\stackrel{*}{y}_{s}(\varepsilon)$ is bounded above by $\sqrt{2} \varepsilon$. Hence for $\varepsilon>0$ sufficiently small, the complete markets allocation Pareto-dominates the incomplete markets allocation. Moreover, a planner who is running the firm could implement the production plan $\hat{y}(\varepsilon)=\left(\begin{array}{c}-2 \\ \varepsilon \\ -\varepsilon\end{array}\right)$ which is not market value maximizing but which offers perfect spanning opportunities. The resulting consumption allocation would be

$$
\hat{x}^{1}=\frac{1}{2}\left(\begin{array}{l}
0 \\
1 \\
1
\end{array}\right)+\frac{1}{2}\left(\begin{array}{c}
0 \\
\varepsilon \\
-\varepsilon
\end{array}\right)=\hat{x}^{2}
$$

which for $\varepsilon>0$ small enough Pareto-dominates the incomplete markets allocation. That is to say the competitive allocation is not constrained Pareto-optimal when markets are incomplete.

Note that the reasoning of Example 1 was done for any objective function of the firm that is exclusively based on the market value criterion. We therefore claim that the failure of constrained Pareto-efficiency to hold in stock market economies is mainly caused by the fact that the market value criterion is insufficient to take into account potential choices for the subspace of traded assets. In order to restore constrained Pareto-efficiency one has the following options:

1. Find a criterion for the selection of production plans which solves the inherent trade-off between spanning and market value maximization, and adjust part 1 of the definition of a competitive equilibrium accordingly.

2. Disentangle the production decision from the question which spanning opportunities are available in the economy.

While option 1 remains unsolved, we propose a solution to option 2 in the remainder of this paper, where we explicitly let the firms make two decisions: a financial decision 


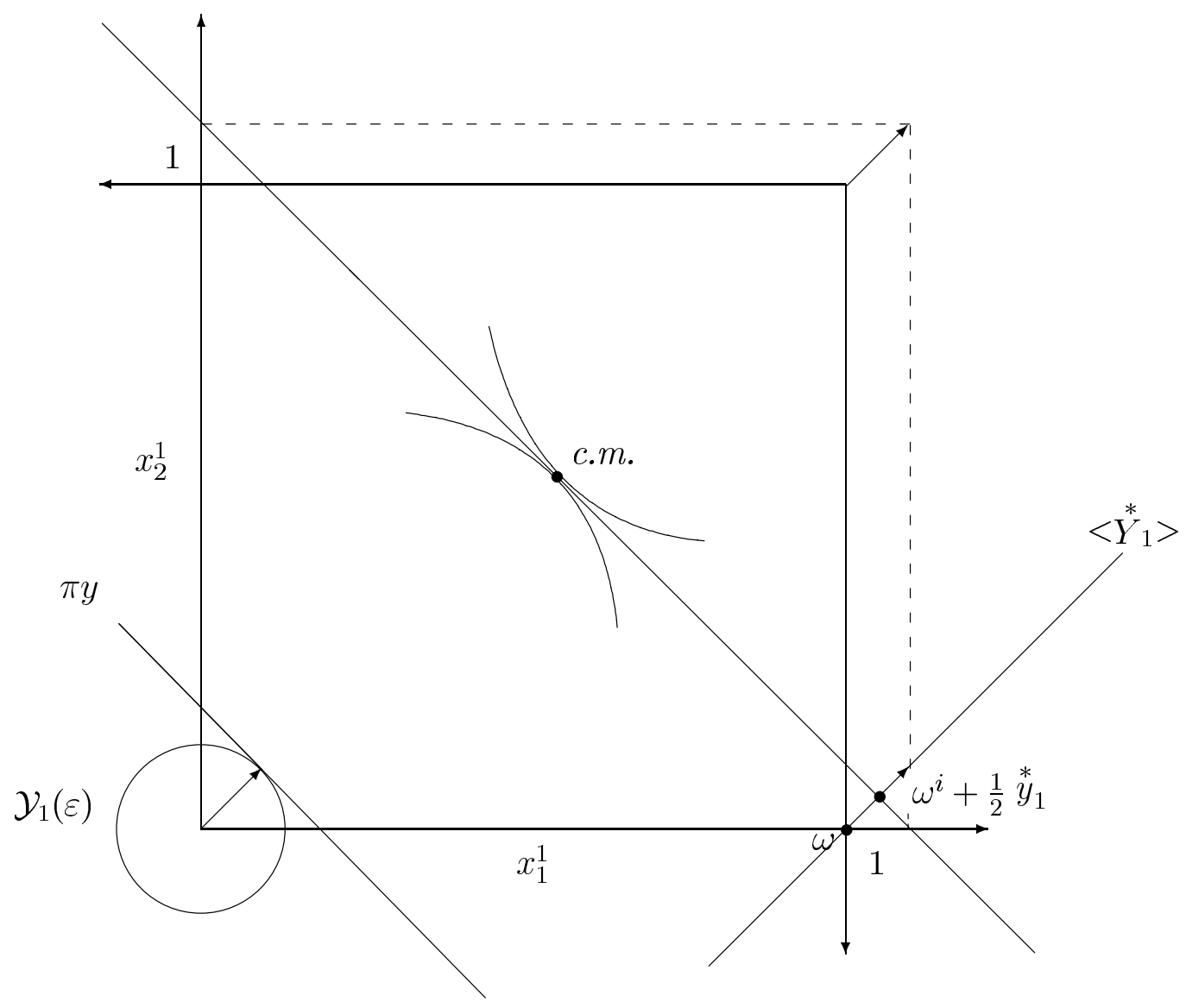

Figure 2: Edgeworth-Box Ex.1 (Illustration)

which is relevant for spanning, and a production decision which maximizes the firms market value.

We conclude this section with a final remark on the literature. Drèze (1974) has introduced a particular market value maximization criterion for firms in stock market economies, namely

$$
\stackrel{*}{\pi}^{k}=\sum_{i=1}^{I}\left(\theta^{*} i+\delta_{k}^{i}\right) \nabla U^{i}\left(\stackrel{*}{x}^{i}\right), \quad k=1, \ldots, K
$$

in which the present value vector used by the firm is the average present value vector of the new shareholders. In this criterion it is important to impose some lower bounds on $\stackrel{*}{\theta}_{k}^{i}$, otherwise the positivity of ${ }^{*} k$ cannot be guaranteed. This however complicates the spanning role of stock market trade. As in Example 1 competitive stock market equilibria based on Drèze's criterion are not necessarily constrained Pareto-efficient but the underlying argument becomes more intricate. To demonstrate the inefficiency result Drèze (1974) gives two examples: one example in which the production choice of the firms provide insufficient spanning, and a second ex- 
ample in which the competitive allocation results in a 'misallocation of ownership'. The idea of his first example is covered by our Example 1 which in contrast to his example is robust with respect to small perturbations of the economy's characteristics. In Drèze's second example, inefficiency is caused by the wrong allocation of ownership. Drèze also gives an example which demonstrates that production efficiency is no prerequisite for constrained Pareto-efficiency. Recently Dierker, Dierker and Grodal (1999) have given further examples demonstrating the constrained inefficiency of competitive equilibria based on the Drèze-criterion. In their examples there is a single firm with a single owner so that inefficiency cannot be attributed to production inefficiency. Dierker, Dierker and Grodal show that the inefficiencies they discover are similar to the inefficiency of marginal cost pricing when production technologies are non-convex (Guesnerie (1975)).

Summarizing this discussion we assert that the Drèze-criterion is a bit cumbersome since the lower bounds on share trades complicate the spanning role of the firm's production decision. Moreover it adds complexity to the inefficiency problem caused by the trade-off between spanning and market value maximization. In the remainder of this paper where we disentangle this trade-off we therefore use the GrossmanHart-criterion instead.

\section{A new objective function for the firm}

\subsection{Relevant financial policy}

The objective functions for the firm which have so far been suggested are all based exclusively on the market value criterion. However, as our Example 1 demonstrates, maximizing market value can be in apparent contrast to the interests of the shareholders when the spanning role of the firm's decision becomes dominant. To serve these two aspects of a firm's decision we suggest to disentangle the market value aspect from the spanning aspect by allowing the firm to engage in a relevant financial policy. We think of the firm as having two departments, the production department and the finance department. Both departments are controlled by the assembly of its shareholders. The production department chooses a production plan which maximizes the firm's market value. In doing so it uses the Grossman-Hart-criterion which was doing fine in partnership economies where market value maximization was the only concern of the shareholders. The finance department can use the production plan $y^{k}$ as a collateral for issuing a new security $a^{k}$ which is supposed to satisfy the shareholders' spanning needs. In fact, we assume that instead of issuing the direct claim on its production plan $y^{K}$ as a share, the firm issues two securities, $a^{k}$ and $\left(y_{1}^{k}-a^{k}\right)$, both in net-supply of $1 .^{8}$ Note that this policy of issuing new securities is a financial policy which cannot be irrelevant in the sense of Modigliani and Miller. New financial securities will typically have a non-trivial effect on the marketed sub-

\footnotetext{
${ }^{8}$ In this set-up, we imagine $S$, the set of possible states of the world, to be very large, and especially to be much larger than the number $N$ of securities which could potentially be innovated by a single firm instead of its shares. For simplicity of the exposition but without loss of generality for the results, we then assume $N=1$.
} 
space, an effect which cannot be undone by the consumers using the existing assets. The firm's production plan $y^{k}$ will typically be non-negative in the second period. Hence the firm is an institution which credibly can promise to deliver the period one payoffs of its financial security. This is the reason why firms play an important role as financial innovators. Of course these reasons are exogenous to the standard incomplete markets model without bankruptcy, and we do not impose any explicit non-negativity restrictions. ${ }^{9}$

The shareholders need to span their complete markets excess demand calculated at prices $\pi^{i}$ which they take as given

$$
\begin{array}{r}
z^{i}\left(\pi^{i}\right):=\arg \max _{z^{i}} U^{i}\left(\omega^{i}+\sum_{k} \delta_{k}^{i} y^{k}+z^{i}\right) \\
\text { s.t. } \pi^{i} \cdot z^{i}=0 \\
\left(\omega^{i}+\sum_{i} \delta_{k}^{i} a^{k}+\sum_{i} \delta_{k}^{i}\left(y^{k}-a^{k}\right)+z^{i}\right) \in \mathcal{X}^{i} .
\end{array}
$$

Of course different shareholders will have different spanning needs and again the firm averages those needs according to the shares of the consumers. This gives a simple rule for the financial innovation decision which reflects the consumers' power in the assembly of the firms' shareholders: ${ }^{10}$

$$
a^{k}=\sum_{i=1}^{I} \delta_{k}^{i} z_{1}^{i}\left(\pi^{i}\right) \quad k=1, \ldots, K
$$

Note that this criterion weighs the spanning interests of the old shareholders which is consistent with the Grossman-Hart criterion for the production decision. From now on we will assume that all financial assets $j=1, \ldots, J$ are issued by firms, i.e. the market subspace $\langle A\rangle$ consists of the linear space spanned by the columns $a^{k}, k=1, \ldots, K$. Adding fixed securities different from $a^{k}$ would not change our results but would unnecessarily complicate our exposition .

Based on these suggestions we can now define a competitive equilibirum in a stock market economy with relevant financial policy. Observe that in this definition we restate the firm's decision problem by choosing the alternative formulation where firm $k$ issues asset $y^{k}$ in net-supply of 1 , and the asset $a^{k}$ in zero net supply. This restatement has been done for consistency with previous definitions only, and does not affect our results.

\footnotetext{
${ }^{9}$ For an incomplete markets model with bankruptcy see Dubey, Geanakoplos, Shubik (1997) and Zame (1993)

${ }^{10}$ Citanna and Villanacci (1996) consider an exchange economy where the consumers act as financial innovators, each of them generating the asset $a^{i}\left(\pi^{i}\right)=z^{i}\left(\pi^{i}\right)$ (using our terminology). Thus, the decision rule suggested by Citanna and Villanacci (1996) can be interpreted as the special case of the decision rule suggested here, when production sets are given by $\mathcal{Y}^{k} \subset \mathbb{R}_{-}^{S+1}$ for $k=1, \ldots, K$, and each firm is owned by exactly one agent.
} 


\section{Definition Stock Market Competitive Equilibrium with Relevant Financial Policy (FM)}

A set of vectors (matrices, resp.) $\left(\stackrel{*}{x}, \stackrel{*}{\theta}, \stackrel{*}{y}, \stackrel{*}{A}, \stackrel{*}{r}, \stackrel{*}{q}, \stackrel{*}{\pi}^{i}\right)$ with $\stackrel{*}{\pi} i \in \mathbb{R}_{++}^{S+1}, \stackrel{*}{\pi}{ }_{0}^{i}=1$ and $\stackrel{*}{\pi}^{i}\left[\begin{array}{cc}-\stackrel{*}{q} & -\stackrel{*}{r} \\ \stackrel{*}{A} & \stackrel{*}{Y}_{1}\end{array}\right]=0$ for every $i=1, \ldots, I$ is a financial markets stock market equilibrium with relevant financial policy if

1. $\stackrel{*}{y}^{k} \in \underset{y^{k} \in \mathcal{Y}^{k}}{\arg \max }\left(\sum_{i} \delta_{k}^{i} \stackrel{*}{\pi^{i}}\right) y^{k}$ for every $k=1, \ldots, K$, and $\stackrel{*}{a^{k}}=\sum_{i} \delta_{k}^{i} \stackrel{*}{z^{i}}$, where

$$
\begin{aligned}
\stackrel{*}{z}^{i} & =\arg \max _{z^{i}} U^{i}\left(\omega^{i}+\sum_{k} \delta_{k}^{i} \stackrel{*}{y}^{k}+z^{i}\right) \\
\text { s.t. } \quad *^{*} \cdot z^{i} & \leq 0 \text { and }\left(\omega^{i}+\sum_{k} \delta_{k}^{i} \stackrel{*}{y}^{k}+z^{i}\right) \in \mathcal{X}^{i}
\end{aligned}
$$

2. $\left(\theta^{i}, *^{i}\right) \in \underset{x^{i} \in \mathcal{X}^{i}, \theta^{i} \in \mathbb{R}^{2 K}}{\arg \max } U^{i}\left(x^{i}\right)$ for every $i=1, \ldots, I$,

s.t. $\left(x^{i}-\omega^{i}-\sum_{k} \delta_{k}^{i} y^{k}\right)=\left[\begin{array}{cc}-\stackrel{*}{q} & -\stackrel{*}{r} \\ \stackrel{*}{A} & Y_{1}^{*}\end{array}\right] \theta^{i}$

3. $\sum_{i} \stackrel{*}{x}^{i}=\sum_{i} \omega^{i}+\sum_{k} \stackrel{*}{y}^{k}$

4. $\sum_{i} \stackrel{*}{\theta}^{i}=0$

Again, there is an equivalent formulation using the no-arbitrage condition.

\section{Definition Stock Market Competitive Equilibrium with Relevant Financial Policy (NA)}

A set of vectors (matrices, resp.) $\left(\stackrel{*}{x}, \stackrel{*}{y}, \stackrel{*}{A}, \stackrel{*}{\pi^{i}}\right)$ with $\stackrel{*}{\pi}^{i} \in R_{++}^{S+1}, \stackrel{*}{\pi}{ }_{0}^{i}=1$ and $\left(\stackrel{*}{\pi}_{1}^{i}-\stackrel{*}{\pi}\right.$ $\left.{ }_{1}^{d}\right)\left[A, \stackrel{*}{Y}_{1}\right]=0$ for every $i, d \in\{1, \ldots, I\}$ is a no-arbitrage competitive equilibrium with relevant financial policy if

1. $\stackrel{*}{y}^{k} \in \underset{y^{k} \in \mathcal{Y}^{k}}{\arg \max }\left(\sum_{i} \delta_{k}^{i} \stackrel{*}{\pi}^{i}\right) y^{k}, \quad a^{k}=\sum_{i} \delta_{k}^{i} \stackrel{*}{z^{i}}$ for every $k=1, \ldots, K$ where

$$
\begin{array}{ll}
\stackrel{*}{z^{i}}=\underset{z^{i}}{\arg \max } U^{i}\left(\omega^{i}+\sum_{k} \delta_{k}^{i} \stackrel{*}{y}^{k}+z^{i}\right), \quad i=1, \ldots, I \\
\text { s.t. } \quad *^{*} \cdot z^{i} \leq 0 \text { and }\left(\omega^{i}+\sum_{k} \delta_{k}^{i} \stackrel{*}{y}^{k}+z^{i}\right) \in \mathcal{X}^{i}
\end{array}
$$


2. $\stackrel{*}{x} i \in \arg \max U^{i}\left(x^{i}\right)$ for every $i=1, \ldots, I$,

$$
\begin{aligned}
& \text { s.t. } \stackrel{*}{\pi}^{i} \cdot\left(x^{i}-\omega^{i}-\sum_{k} \delta_{k}^{i} \stackrel{*}{y}^{k}\right)=0, \\
& \text { and }\left(x_{1}^{i}-\omega_{1}^{i}-\sum_{k} \delta_{k}^{i} \stackrel{*}{y}_{1}^{k}\right) \in<\stackrel{*}{A}, \stackrel{*}{Y}_{1}>
\end{aligned}
$$

3. $\sum_{i} \stackrel{*}{x}^{i}=\sum_{i} \omega^{i}+\sum_{k} \stackrel{*}{y}^{k}$

Some remarks will be useful in order to explain this equilibrium concept. Firstly, note that the equilibrium is competitive in the traditional sense, i.e. no agent makes any strategic conjectures about the way in which her actions will influence the equilibrium outcome. Consumer $i$ simply takes the prices $\stackrel{*}{\pi} i$, the production plans $\stackrel{*}{y}$, and the financial policies $\stackrel{*}{A}$ as given. Producers take the prices $\stackrel{*}{\pi}^{i}$ and the complete market demands $\stackrel{*}{z}^{i}$ of their shareholders as given. Secondly, observe that the consumers' state prices are treated as exogenous; hence, the competitive equilibria defined above are indeterminate. Moreover, thirdly, the vector of state prices $\pi^{i}$ will not necessarily coincide with the consumers' utility gradient vectors $\nabla U^{i}\left({ }^{*} i\right)$. There is no harm in replacing $\stackrel{*}{\pi}^{i}$ by $\nabla U^{i}\left(\stackrel{*}{x}^{i}\right)$ as far as the production decision $\stackrel{*}{y}^{k}$ is concerned. This would rather rule out the indeterminacy coming from changes in the production plans induced by different choices of the state prices $\stackrel{*}{*}^{i}$. Replacing it in the financial decision of the firm, however, would make this policy irrelevant: In fact, for any $\left[\hat{A}, \hat{Y}_{1}\right]$ it is obtained that $z^{i}\left(\nabla U^{i}\left(\hat{x}^{i}\right)\right) \in<\hat{A}, \hat{Y}_{1}>$, where $\hat{x}^{i}$ is any consumption plan that is utility maximizing given the set of financial assets $\left(\hat{A}, \hat{Y}_{1}\right)$ (i.e. $\hat{x} \in$ $\arg \max _{x^{i} \in \mathcal{X}^{i}} U^{i}\left(x^{i}\right)$ s.t. $\nabla U^{i}\left(\hat{x}^{i}\right) \cdot\left(x^{i}-\omega^{i}-\sum_{k} \delta_{k}^{i} \hat{y}^{k}\right)=0$ and $\left(x_{1}^{i}-\omega_{1}^{i}-\sum_{k} \delta_{k}^{i} \hat{y}_{1}^{k}\right) \in<$ $\left.\hat{A}, \hat{Y}_{1}>\right)$.

The role of the state prices $\stackrel{*}{\pi}^{i}$ is analyzed in more depth in the following subsection. First, however, we will give an example which demonstrates that the competitive equilibria defined above are not necessarily constrained Pareto-efficient unless further restrictions are imposed. As in Example 1, constrained Pareto-inefficiency arises from the fact that the spanning opportunities might be inefficient. However, in contrast to Example 1, this inefficiency does not result from an inefficient trade-off between the production decisions. Rather, inefficiency here results from inefficient financial innovation chosen by the firms' financial departments. ${ }^{11}$

Example 2: Consider an economy with I 'unproductive' firms, i.e. $\mathcal{Y}^{k} \subset \mathbb{R}_{-}^{S+1}$ for every $k=1, \ldots, I$. Let $\left(\stackrel{*}{\pi}, z^{i}(\stackrel{*}{\pi})\right)$ be a competitive equilibrium for the corresponding Arrow-Debreu exchange economy, i.e. let

$$
\sum_{i} z^{i}(*)=0, \text { where for all } i=1, \ldots, I
$$

\footnotetext{
${ }^{11}$ The following example illustrates an important result derived by Citanna and Villanacci (1996). They show that equilibria with various degrees of "market incompleteness" can coexist in an exchange economy where consumers also act as financial innovators: no innovation at all, innovation of an incomplete set of securities, and innovation of a complete set of securities.
} 


$$
\begin{aligned}
& z^{i}\left(\pi^{*}\right)=\arg \max _{z^{i}} U^{i}\left(\omega^{i}+z^{i}\right), \\
\text { s.t. } & * z^{i} \leq 0 \text { and }\left(\omega^{i}+z^{i}\right) \in \mathcal{X}^{i} .
\end{aligned}
$$

Suppose that $U^{i}\left(\omega^{i}+z^{i}\left(*^{*}\right)\right)>U^{i}\left(\omega^{i}\right)$ for all $i=1, \ldots, I$ and that

$$
\delta_{k}^{i}=\left\{\begin{array}{ll}
1 & k=i \\
0 & k \neq i
\end{array}, \quad i, k=1, \ldots, I .\right.
$$

This economy has at least the following two stock market competitive equilibria with relevant financial policy:

The first equilibrium results from the observation that $z^{i}\left(\nabla U^{i}\left(\omega^{i}\right)\right)=0, \quad i=1, \ldots, I$ :

$$
\begin{array}{ll}
\stackrel{*}{x}^{i}=\omega^{i}, & i=1, \ldots, I \\
\stackrel{*}{y}^{k}=0, & k=1, \ldots, K \\
\stackrel{*}{a}^{k}=0, & k=1, \ldots, K \\
\stackrel{*}{\pi}^{i}=\nabla U^{i}\left(\omega^{i}\right), & i=1, \ldots, I
\end{array}
$$

The second equilibrium, however, is given by the following set of vectors:

$$
\begin{array}{ll}
\stackrel{*}{x}^{i}=\omega^{i}+\stackrel{*}{z}^{i}, & i=1, \ldots, I \\
\stackrel{*}{y}^{k}=0, & k=1, \ldots, I \\
\stackrel{*}{*}^{k}=\stackrel{*}{z}^{k}, & k=1, \ldots, I \\
\stackrel{*}{\pi}^{i}=\stackrel{*}{\pi}, & i=1, \ldots, I
\end{array}
$$

Hence the second equilibrium Pareto-dominates the first.

The fact that firms choose an inefficient set of innovated assets is based on the lack of unanimity of the consumers ${ }^{6}$ state prices $\pi^{*}$. Indeed, examples of this kind will persist in stock market competitive equilibria with relevant financial policy as long as agents' beliefs are heterogeneous. The following subsection will therefore introduce a framework to guarantee homogeneous beliefs in the economy.

\subsection{Communication of beliefs}

The role of beliefs

Introducing communication into interactive decision problems seems to be in conflict with the presumed non-cooperative behavior of the agents. Game theorists should be credited for having done the first steps in this direction. The notion of 'preplay communication' or 'cheap talk' has been successfully introduced to solve some puzzles of non-cooperative game theory like the coordination on Pareto-efficient Nashequilibria (c.f. Matsui (1991)). Similarly, in our context communication can help to select Pareto-efficient equilibria. In fact, the fundamental problem of incomplete markets is that the prices $(\stackrel{*}{q}, \stackrel{*}{r})$ quoted by the auctioneer do not provide sufficient information how to evaluate an arbitrary payoff stream $y_{1} \in \mathbb{R}^{S}$. While the evaluation of those components of $y_{1}$ lying in the marketed subspace is unambiguous, the 
evaluation of the complementary components cannot be inferred from the asset and stock market prices. At any equilibrium $(\stackrel{*}{x}, \stackrel{*}{y}, \stackrel{*}{A}, \stackrel{*}{\pi})$, however, every production plan is unambiguously priced because obviously then $\stackrel{*}{y}_{1}$ lies in the marketed subspace $<\stackrel{*}{A}, \stackrel{*}{Y}_{1}>$. In order to evaluate alternative production plans it would therefore be best to know the resulting equilibrium. This knowledge, of course, is hard to get. However agents might still form some beliefs about equilibrium prices. We therefore suggest to interpret $\stackrel{*}{*}^{i}$ as being consumer $i$ 's belief on the equilibrium state-prices.

Note that beliefs are based on the actual asset-stock-prices quoted by the auctioneer and that agents hold point expectations. Hence, given the belief $\pi^{*}$, agent $\mathrm{i}$ wants firm $\mathrm{k}$ to maximize the market value $\stackrel{*}{*}^{i} \cdot y^{k}$. Other agents may hold different beliefs and we assume that the decision of the assembly of shareholders will reflect their influence on the firm's market value objective, i.e. $\sum_{i} \delta_{k}^{i}{ }^{*} i \cdot y^{k}$ is a natural objective function in this respect. To understand the conceptual difference of this objective function and the Grossman-Hart-criterion it is important to recall that the agents' beliefs $\stackrel{*}{\pi}^{i}$ will not necessarily coincide with their normalized utility gradient $\nabla U^{i}\left(\stackrel{*}{x}^{i}\right)$.

As long as agents are not taking into consideration that alternative production plans change the equilibrium allocation, the Grossman-Hart criterion seems to be in the best interest of the shareholders. This reasoning is well justified for spanned production plans; however, this point of view cannot be justified for unspanned production plans. Unspanned production plans may induce dramatic changes to the marketed subspace irrespectively of how small the innovating firm is relative to the whole production sector. Since such competitive price perceptions cannot be justified in the standard model, we have here assumed that consumers hold beliefs about the resulting equilibrium prices. Based on these beliefs, $\pi^{i}$, consumers calculate their spanning needs $z^{i}\left(\pi^{i}\right)$, and the different needs of the shareholders will be averaged according to their possession of shares.

\section{Consistency of beliefs}

It is natural to assume that consumers meet other consumers (for example in the assemblies of the firms' shareholders), and that in these meetings they exchange their different views on the expected equilibrium state-prices. Hence in forming their beliefs consumers will be influenced by the beliefs of the other consumers. To ensure consistency between the indiviual beliefs, we propose the following rather simple consistency requirement:

$$
\pi^{i}=\sum_{j=1}^{I} h_{j}^{i} \pi^{j}, \quad \text { for every } i=1, \ldots, I,
$$

where $h_{j}^{i} \geq 0$, and, as a matter of normalization, $\sum_{j=1}^{I} h_{j}^{i}=1$. Hence agents form their beliefs by taking convex combinations of all the other agents' beliefs. A special case arises if agents put strictly put positive weights only on those agents (including themselves) with whom they share a firm. In this case, the weights $h$ are given by $h_{j}^{i}>0$ if and only if there exists some $k \in K$ such that $\delta_{k}^{i} \delta_{k}^{j}>0$. 
We can now propose the following new equilibrium concept:

\section{Definition Stock Market Competitive Equilibrium with Relevant Financial Policy and Communication (FM)}

A set of vectors (matrices, resp.) $(\stackrel{*}{x}, \stackrel{*}{\theta}, \stackrel{*}{Y}, \stackrel{*}{A}, \stackrel{*}{r}, \stackrel{*}{q}, \stackrel{*}{\pi} i)$ with $\stackrel{*}{\pi} i \in \mathbb{R}_{++}^{S+1}, \stackrel{*}{\pi}{ }_{0}^{i}=1$, $\stackrel{*}{\pi}^{i}\left[\begin{array}{cc}-\stackrel{*}{q} & -\stackrel{*}{r} \\ \stackrel{*}{A} & \stackrel{*}{Y_{1}}\end{array}\right]=0$ and $\stackrel{*}{*}^{i}=\sum_{j} h_{j}^{i} \stackrel{*}{\pi}^{j}$ for every $i=1, \ldots, I$ is a financial markets competitive equilibrium with relevant financial policy and communication if

1. $\stackrel{*}{y}^{k} \in \underset{y^{k} \in \mathcal{Y}^{k}}{\arg \max }\left(\sum_{i} \delta_{k}^{i} \stackrel{*}{\pi}^{i}\right) y^{k}$, and $\stackrel{*}{a}^{k}=\sum_{i=1}^{I} \delta_{k}^{i} \stackrel{*}{z}^{i}$ for every $k=1, \ldots, K$, where

$$
\begin{array}{ll}
\stackrel{*^{i}}{z^{i}}=\underset{z^{i}}{\arg \max } U^{i}\left(\omega^{i}+\sum_{k} \delta_{k}^{i} \stackrel{*}{y}^{k}+z^{i}\right), \quad i=1, \ldots, I \\
\text { s.t. } \quad \stackrel{*}{\pi} i^{i} \cdot z^{i} \leq 0 \text { and }\left(\omega^{i}+\sum_{k} \delta_{k}^{i} \stackrel{*}{y}^{k}+z^{i}\right) \in \mathcal{X}^{i}
\end{array}
$$

2. $\left(\stackrel{*}{\theta}^{i}, \stackrel{*}{x}^{i}\right) \in \arg \max U^{i}\left(x^{i}\right)$

$$
\begin{aligned}
& \text { s.t. }\left(x^{i}-\omega^{i}-\sum_{k} \delta_{k}^{i} \stackrel{*}{y}^{k}\right)=\left[\begin{array}{cc}
-\stackrel{*}{q} & \stackrel{*}{r} \\
\stackrel{*}{*} & \stackrel{*}{Y_{1}}
\end{array}\right] \theta^{i} \\
& \text { 3. } \sum_{i} \stackrel{*}{x}^{i}=\sum_{i} \omega^{i}+\sum_{k} \stackrel{*}{y}^{k} \\
& \text { 4. } \sum_{i} \stackrel{*}{\theta}^{i}=0
\end{aligned}
$$

In its no-arbitrage form this definition reduces to:

\section{Definition Competitive Stock Market Equilibrium with Relevant Financial Policy and Communication (NA)}

A set of vectors (matrices, resp.) $(\stackrel{*}{x}, \stackrel{*}{Y}, \stackrel{*}{A}, \stackrel{*}{*} i)$ with $\stackrel{*}{\pi} i \in \mathbb{R}_{++}^{S+1}, \stackrel{*}{\pi}_{0}^{i}=1,(\stackrel{*}{\pi} d-\stackrel{*}{\pi})[\stackrel{*}{A}$ ,$\left.\stackrel{*}{Y}_{1}\right]=0$, and $\stackrel{*}{\pi}^{i}=\sum_{j} h_{j}^{i} \stackrel{*}{\pi}^{j}$ for every $i, d=1, \ldots, I$ is a no-arbitrage competitive stock market equilibirum with relevant fiancial policy and communication if

1. $\stackrel{*}{y}^{k} \in \underset{y^{k} \in \mathcal{Y}^{k}}{\arg \max }\left(\sum_{i} \delta_{k}^{i} \stackrel{*}{*}^{i}\right) y^{k}$, and $\stackrel{*}{a}^{k}=\sum_{i=1}^{I} \delta_{k}^{i} \stackrel{*}{z}^{i}$ for every $k=1, \ldots, K$, where

$$
\begin{array}{ll} 
& \stackrel{*}{z^{i}}=\underset{z^{i} \in \mathbb{R}^{S+I}}{\arg \max } U^{i}\left(\omega^{i}+\sum_{k} \delta_{k}^{i} \stackrel{*}{y}^{k}+z^{i}\right) \\
\text { s.t. } & *^{*} \cdot z^{i} \leq 0 \text { and }\left(\omega^{i}+\sum_{k} \delta_{k}^{i} \stackrel{*}{y}^{k}+z^{i}\right) \in \mathcal{X}^{i}
\end{array}
$$


2. $\stackrel{*}{x}^{i} \in \underset{x^{i} \in \mathcal{X}^{i}}{\arg \max } U^{i}\left(x^{i}\right)$ for every $i=1 ; \ldots, I$,

$$
\begin{aligned}
& \text { s.t. } \stackrel{*}{\pi}^{i} \cdot\left(x^{i}-\omega^{i}-\sum_{k} \delta_{k}^{i} \stackrel{*}{y}^{k}\right)=0, \text { and } \\
& \left(x_{1}^{i}-\omega_{1}^{i}-\sum_{k} \delta_{k}^{i} \stackrel{*}{y}_{1}^{k}\right) \in<\stackrel{*}{A}, \stackrel{*}{Y}_{1}>
\end{aligned}
$$

3. $\sum_{i} \stackrel{*}{x}^{i}=\sum_{i} \omega^{i}+\sum_{k} \stackrel{*}{y}^{k}$

In the 'communication network' we can think of every consumer as a node in a graph summarized by the following $I \times I$ matrix $H=\left[\begin{array}{llr}h_{1}^{1} & \ldots & h_{I}^{1} \\ \vdots & \vdots & \vdots \\ h_{1}^{I} & \ldots & h_{I}^{I}\end{array}\right]$. How useful for a competitive equilibrium the introduction of communication is will depend on the structure of this graph. For example, if there is no communication $(H=I d)$, then beliefs are still exogenous in the new equilibrium notion .

We say consumer i is 'directly connected' to consumer $\mathrm{j}$ if $h_{j}^{i}>0$, and we say consumer $\mathrm{i}$ is connected to consumer $\mathrm{j}$ if there is some chain of directly connected consumers connecting $\mathrm{i}$ and $\mathrm{j}$. This defines a 'directed communication graph'. Analogously one can define an undirected communication graph by saying $\mathrm{i}$ is connected to $\mathrm{j}$ if for some chain of consumers $k_{1}, \ldots, k_{n} \in I$ in any pair of neighbours $k_{j}, k_{j+1}$ either $\mathrm{j}$ is directly connected to $j+1$ or $j+1$ is directly connected to $\mathrm{j}$.

Generally speaking, agents' beliefs will become more homogeneous the more the communication graphs are connected. And if two subsets of consumers are not connected then across those subjects beliefs can remain different.

The next proposition proves that beliefs will become homogeneous when the following notion of 'belief connectedness' is satisfied:

\section{Definition}

The economy is belief connected if

$$
\exists d \in I: \forall J \subset I \backslash\{d\} \exists i \in J \text { with } h_{j}^{i}>0 \text { some } j \in I \backslash J .
$$

This notion looks a bit cumbersome but it is the weakest notion of connectedness we can provide, which still implies homogeneous beliefs. It is directly related to the connectedness of the directed communication graph (henceforth referred to as 'strong connectedness' of the communication network) and the connectedness of the undirected communication graph ('weak connectedness').

\section{Definition}

The communication network is strongly connected if

$$
\forall(i, j) \in I \times I \quad \exists k_{1}, \ldots, k_{n} \in I: h_{k_{1}}^{i} \cdot h_{k_{2}}^{k_{1}} \cdots h_{j}^{k_{n}}>0 .
$$




\section{Definition}

The communication network is weakly connected if

$$
\forall(i, j) \in I \times I \quad \exists k_{1}, \ldots, k_{n} \in I:\left(h_{k_{1}}^{i}+h_{i}^{k_{1}}\right)\left(h_{k_{2}}^{k_{1}}+h_{k_{1}}^{k_{2}}\right) \cdots\left(h_{j}^{k_{n}}+h_{k_{n}}^{j}\right)>0 .
$$

The following proposition shows that strong connectedness is, in fact, a stronger condition than belief connectedness, while weak connectedness is a weaker condition.

\section{Proposition 1}

If the communication network is strongly connected then the economy is belief connected and if the economy is belief connected then the communication network is weakly connected. Moreover these implications are strict.

\section{Proof:}

If the directed communication network is connected then $\forall d \in I$ and $\forall J \subset I \backslash$ $\{d\}$ there $\exists i \in J$ such that $h_{j}^{i}>0$ some $j \in I \backslash J$. Otherwise k would not be connected to $I \backslash J$. Hence the economy is belief connected. To see that the converse is not true imagine an economy in which every consumer puts positive weight on the belief of some universally accepted 'expert' $d \in I$, while the expert himself only believes in his own views, i.e. $\exists d \in I$ such that $\forall i \in I \quad h_{d}^{i}>0$ and $h_{d}^{d}=1$.

Now suppose the undirected communication network is not connected, i.e. $\exists D \subset I$ such that $h_{i}^{d}=0$ and $h_{d}^{i}=0$ all $d \in D$ all $i \in I \backslash D$. Then for any $d \in I$ we get that the requirement in the definition of belief connectedness is not satisfied. If $d \in D$ then this requirement is not satisfied for $J=I \backslash D$. And if $d \notin D$ then the requirement does not hold for $J=D$. Hence the economy is not belief connected.

To see that the converse is not true consider the communication network $H=$
$\left[\begin{array}{ccc}1 & 0 & 0 \\ 0 & 1 & 0 \\ .5 & .5 & 0\end{array}\right]$. Since agent 3 is directly connected to agents 1 and 2 the undirected communication network is connected. Now trying to find a $d \in I$ such that the economy is belief connected we see that if

$d=1 \quad$ for $J=\{2\} \quad$ there is no $i \in J$ with $h_{j}^{i}>0$ some $j \in I \backslash J$

$d=2$ for $J=\{1\}$

$d=3$ for $J=\{1,2\}$

hence the economy is not belief connected.

The last example given in the proof of Proposition 1 shows that communication of beliefs does not necessarily imply identical beliefs of the agents. If agents 1 and 2 hold 
different beliefs, then there is no way of changing them since both agents only believe in their own views. Hence, weak connectedness of the communication network does not imply homogeneous beliefs of the agents. The next proposition shows, however, that the assumption of belief connectedness suffices to imply homogeneous beliefs.

\section{Proposition 2}

If the economy is belief connected then the communication of beliefs leads to homogeneous beliefs.

\section{Proof:}

Consider any state $s=0, \ldots, S$. We will show that $\pi_{s}^{i}=\pi_{s}^{j}$ for all $(i, j) \in I \times I$. Define the vectors $\pi_{s}:=\left(\pi_{s}^{1}, \ldots, \pi_{s}^{I}\right)^{T} \in \mathbb{R}_{++}^{S+1}$. Then $\pi_{s}=H \pi_{s}$ from the consistency requirement with respect to state s. The fact that $\sum_{j} h_{j}^{i}=1$ then implies that $\stackrel{*}{\pi}_{s}=\lambda(1, \ldots, 1)$ for some $\lambda \in \mathbb{R}_{++}$is a strictly positive solution to this system of equations.

We need to show that $\stackrel{*}{\pi}_{s}$ is the unique solution. To this end we show that $(I d-H)$ has rank $I-1$, where $I d$ denotes the identity matrix of dimension $\mathrm{I}$.

By the assumption of belief connectedness there exists some $d \in I$ such that for all subsets $J \subset I \backslash\{d\} \quad h_{j}^{i}>0$ for some $(i, j) \in J \times(I \backslash J)$. Consider the $(I-1) \times(I-1)$ submatrix in which the d-th row and the d-th column of the matrix $(I d-H)$ have been cancelled. From the assumption of belief connectedness we see that $1 \geq \sum_{j \in I \backslash d} h_{j}^{i}$ for every $i=1, \ldots I, i \neq d$, where at least one inequality is strict. That is to say the $(I-1) \times(I-1)$ submatrix is 'quasi-diagonal dominant'. A result of Uekawa (1971) now implies that this matrix has full rank $I-1$ (see Murata (1977), Theorem 21).

Note that in the special case where agents are connected if they meet in the assembly of shareholders (i.e. $h_{j}^{i}>0$ if and only if $\delta_{k}^{i} \delta_{k}^{j}>0$ for some $k=1, \ldots, K$ ), the matrix $H$ is symmetric in the sense that $h_{j}^{i}>0$ if and only if $h_{i}^{j}>0$. In this case, the definitions of "strong", "weak", and "belief" connectedness are equivalent.

Note that homogeneity of beliefs implies that the production decision of the firm is independent from the composition of its set of shareholders, i.e. the FisherSeparation-Principle holds. Moreover in this case all firms evaluate their production plans according to the same price vector so that production efficiency is also obtained by the homogeneity of beliefs.

\section{Updating beliefs}

A different way of obtaining homogeneous beliefs is to model communication by some iterative process along which agents update their beliefs. Following this idea 
we define the updating rule as

$$
\pi^{i}(t+1)=\sum_{j=1}^{I} h_{j}^{i}(t) \pi^{i}(t), \quad t=0,1,2, \ldots
$$

Of course time ' $t$ ' cannot be thought of as real time but rather as mental time. This notion of mental time is often used in economics. See for example the process of 'ficticious play' used in game theory or Roger Guesnerie's deductive justification of rational expectations.

Note that along the updating process agents are not supposed to keep the weights for averaging constant! As before we assume that $h_{j}^{i}(t) \geq 0$ and $\sum_{j} h_{j}^{i}(t)=1$ for every $t \geq 0$. Hence, the updating rule defines a finite Markov chain. Applying standard results of the theory of Markov chains we get:

\section{Proposition 3}

Suppose from some period $n$ onwards all agents' weights $h_{j}^{i}(t)$ are bounded below by some positive real number $\varepsilon>0$ then all agents' beliefs converge to the same belief, i.e. if there exists some $n \in \mathbb{N}$ such that for all $t \geq n$ and for all $(i, j) \in I^{2}$ it follows that $h_{j}^{i}(t) \geq \varepsilon>0$ for some $\varepsilon \in \mathbb{R}$, then $\lim _{t \rightarrow \infty} \pi^{i}(t)=\bar{\pi} \in \mathbb{R}_{++}^{S+1}, \quad i=1, \ldots, I$.

\section{Proof:}

As in the proof of proposition 2 for any $s=0, \ldots, S$ consider the recursion $\pi_{s}(t)=$ $H(t-1) \pi_{s}(t-1)$, hence $\pi_{s}(T)=\left(\prod_{t=0}^{T} H(t)\right) \pi_{s}(0)$. The proposition is then an immediate consequence of Theorem 4.1.3 in Kemeny and Snell (1976).

As a corollary of this proposition we get

\section{Corollary 2}

Suppose that from some period onwards the updating rule is stationary and given by the matrix $H$ of a strongly connected communication network. Then all agents' beliefs converge to the same belief.

\section{Proof:}

If $\mathrm{H}$ is strongly connected, then there exists some $m \in \mathbb{N}$ such that $H^{m}>>0$.

As in the previous proofs consider the recursion

$$
\pi_{s}(T)=\left(\prod_{t=0}^{T} H(t)\right) \pi_{s}(0)=H^{T} \pi_{s}(0) .
$$

The last equation follows from the stationarity assumption. Hence $\pi_{s}(\infty)=\left(\lim _{T \rightarrow \infty} H^{T}\right) \pi_{s}(0)$. Note that $\lim _{T \rightarrow \infty} H^{T}=\lim _{n \rightarrow \infty}\left(H^{m}\right)^{n}$. Moreover since $H^{m}>>0$, there exists some $\varepsilon \geq 0$ 
such that $h_{j}^{i} \geq \varepsilon>0$ and the result follows from the previous proposition.

\section{Pareto-efficiency of Stock Market Economies}

In this section we will show that using our previous arguments Pareto-efficiency of stock market economies can be obtained if and only if there are 'sufficiently many' firms. The number of firms is sufficient in this sense if there are at least as many firms as there are risks or if there are at least as many firms as there are consumers. Of course there might be some exceptional cases where even a very large number of firms is not sufficient for our result because either all firms' technologies are very similar or their composition of shareholders is not heterogeneous enough to guarantee effective communication. Therefore, the economy is parameterized by some vectors of firms' endowments $\eta^{k} \in \mathbb{R}^{S+1}, \quad k=1, \ldots, K$, with $\left(\eta^{1}, \ldots, \eta^{K}\right) \in N$ for some large set $N \subset \mathbb{R}^{(S+1) K}$, which allows us to perturb the firms' production technologies. Furthermore, the economy is parameterized by the consumers' initial shareholdings $\delta^{i} \in[0,1]^{K}, \quad i=1, \ldots, I$, with $\delta^{1}, \ldots, \delta^{I} \in D=\left\{\delta^{i} \in[0,1]^{K} \mid \sum_{i} \delta_{k}^{i}=1, \quad k=\right.$ $1, \ldots, K\}$.

The first result shows that if $K \geq S$ then markets are complete because, generically in the firms' endowments, the production plans ${ }^{*}{ }^{k}$ (for $k=1, \ldots, K$ ) span all risks. This result is essentially due to Duffie and Shafer (1988) who consider a stock market economy without relevant financial policy for which they assume homogeneity of beliefs. In our setting, however, this result is rather restrictive since we have in mind that $S$ is very large.

\section{Theorem 3}

Suppose the economy is belief connected. Then, for a generic set of firms' endowments, competitive stock market equilibria with communication are Pareto-efficient provided there are at least as many firms as there are risks in the economy.

\section{Proof:}

Belief connectedness implies homogeneity of beliefs (Proposition 2). Given any state price vector $\stackrel{*}{\pi} \in \mathbb{R}_{++}^{S+1}$, generically in $\eta$, the collection of production plans $\stackrel{*}{y}^{k}=\arg \max _{y^{k} \in \mathcal{Y}^{k}\left(\eta^{k}\right)} \stackrel{*}{\pi} \cdot y^{k}, \quad k=1, \ldots, K$ is linearly independent (Duffie and Shafer (1988)). Hence markets are complete, i.e. $\left\langle\stackrel{*}{Y_{1}}\right\rangle=\mathbb{R}^{S}$ and the stock market equilibrium is a complete markets equilibrium. Pareto-efficiency then follows from the first welfare Theorem. 
Note that belief connectedness itself is not sufficient to imply Pareto-efficiency if the number of firms is not sufficiently large and no relevant financial policy is possible. This claim follows from a reconsideration of our Example 1. In this example, assigning any strictly positive vector of state prices to the firm will lead to the choice of production plans which prohibit risk sharing! In particular the firms' state price vectors can be chosen to be the homogeneous beliefs which agents might hold.

Now suppose, however, that the firm in Example 1 could make two separate decisions: On the one hand it chooses a production plan such as to maximize the firms' market value, on the other hand, and completely independently, it issues a financial security such as to accomodate its shareholders spanning needs. Then complete risk sharing would be provided and a Pareto-efficient solution would be achieved.

\section{Example 1 (continued)}

Slightly modifying the assumptions, assume now that $\delta^{1}=1 / 4$ and $\delta^{2}=3 / 4$, i.e. that ownership in the firm is no longer equally shared between the consumers. ${ }^{12} \mathrm{We}$ claim that the Pareto-efficient allocation

$$
\begin{aligned}
& \stackrel{*}{x}^{1}=\frac{1}{4}(0,2+\varepsilon, 2+\varepsilon) \text { and } \\
& \stackrel{*}{x}^{2}=\frac{1}{4}(0,2+3 \varepsilon, 2+3 \varepsilon)
\end{aligned}
$$

is a competitive equilibrium with relevant financial policy and communication. In fact, letting $\stackrel{*}{\pi}^{i}=(1,1,1), i=1,2$, all consistency requirements are met. Then $\stackrel{*}{y}=(-2, \varepsilon, \varepsilon)$ and hence

$$
\begin{aligned}
z^{1}(*) & =\frac{1}{4}(-2,2) \text { and } \\
z^{2}(*) & =\frac{1}{4}(2,-2) .
\end{aligned}
$$

Hence the firm will innovate the financial asset

$$
\stackrel{*}{a}=\frac{1}{4} \stackrel{*}{z} 1+\frac{3}{4} \stackrel{*}{z}^{2}=\frac{1}{4}(1,-1)
$$

But this is exactly the asset, which the consumers need to effectuate their desired net-trades, i.e.

$$
\left(\stackrel{*}{x}_{1}^{i}-\delta^{i} \stackrel{*}{y_{1}}-\omega_{1}^{i}\right) \in \stackrel{*}{a}^{*}>
$$

Hence, by disentangling the problems of market value maximization and of financial innovation, complete risk sharing in the economy can be obtained. The following theorem shows that this point is true in general. It is important to note here, that,

\footnotetext{
${ }^{12}$ Otherwise the rank condition stated in the following theorem is no longer satisfied.
} 
in contrast to Theorem 3 above, the following result does not impose any restrictions on $S$, that is on the magnitude of the number of potential states of the world.

\section{Theorem 4}

Suppose the economy is belief connected and rank $\triangle=I$ or rank $\left[\triangle^{\backslash d}-\delta^{d} \mathbb{I}\right]=\mathrm{I}-1$ for some $d \in\{1, \ldots, I\}$. Then competitive stock market equilibria with relevant financial policy and communication are Pareto-efficient ${ }^{13}$.

\section{Proof:}

The result follows from the claim that under the assumptions stated a stock market equilibrium with relevant financial policy and communication is, in fact, also an Arrow-Debreu-equilibrium allocation.

To prove this claim, let

$$
\left(\left(\stackrel{*}{\pi}^{i}, \stackrel{*}{x}\right)_{i=1, \ldots, I}, \stackrel{*}{Y}, \stackrel{*}{A}\right)
$$

be a stock market equilibrium with relevant financial policy and communication (NA). From Proposition 2 we know that belief connectedness implies that

$$
*^{*}=*^{2}=\ldots=*^{*} I=* *
$$

We claim that ${ }^{*}$ is an equilibrium state price vector for the Arrow-Debreu-model. First note, that the production decision of the firm is the same for both equilibrium concepts. Secondly, note that both concepts have the same market clearing conditions. Thus, it only remains to show that the consumption decisions of the agents remain unchanged when moving from the stock market model to the Arrow-Debreu situation. To show this it suffices to prove that the agents complete markets demand is spanned, i.e. that

$$
z^{i}(\stackrel{*}{\pi}) \in<\stackrel{*}{Y_{1}}, \stackrel{*}{A}>.
$$

In the first case this claim follows from the equilibrium condition

$$
\stackrel{*}{A}=\stackrel{*}{Z} \cdot \Delta^{T}
$$

by observing that under the assumptions made the matrix of share ownership $\Delta^{T}$ has a right inverse.

To see the second case, suppose that there exists some $d \in\{1, \ldots, I\}$ such that rank $\left[\triangle^{\backslash d}-\delta^{d} \mathbb{I}\right]=\mathrm{I}-1$. Since then $\stackrel{*}{z}^{i}$ corresponds to the equilibrium net trades in the complete markets model, it follows that $z_{1}^{d}\left({ }^{*}\right)=-\sum_{i \neq d} z_{1}^{i}\left({ }^{*}\right)$. Hence firm k's financial policy can be written as

$$
\begin{aligned}
a^{k} & =\sum_{i=1}^{I} \delta_{k}^{i} z_{1}^{i}(*) \\
& =\sum_{i \neq d}\left(\delta_{k}^{i}-\delta_{k}^{d}\right) z_{1}^{d}\left(\pi^{*}\right), k=1, \ldots, K .
\end{aligned}
$$

\footnotetext{
${ }^{13}$ We use the following notation: $\triangle=\left[\delta^{1}, \ldots, \delta^{I}\right] \in \mathbb{R}^{K \times I}, \triangle^{\backslash d}=\left[\delta^{1}, \ldots, \delta^{d-1}, \delta^{d+1}, \ldots, \delta^{I}\right] \in$ $\mathbb{R}^{K \times(I-1)}, \quad A=\left[a^{1}, \ldots, a^{K}\right] \in \mathbb{R}^{S \times K}, \quad Z_{1}=\left[z_{1}^{1}, \ldots, z_{1}^{I}\right] \in \mathbb{R}^{S \times I}, \quad Z_{1}^{\backslash d}=$ $\left[z_{1}^{1}, \ldots, z_{1}^{d-1}, z_{1}^{d+1}, \ldots, z^{I}\right] \in \mathbb{R}^{S \times(I-1)}, \mathbb{I}=(1, \ldots, 1) \in \mathbb{R}^{\mathrm{I}-1}$.
} 
Written more compactly, this is:

$$
\begin{aligned}
& A=\quad Z_{1}^{\backslash d}\left[\triangle^{\backslash d}-\delta^{d} \mathbb{I}\right] \text {. Solving for } Z_{1}^{\backslash \mathrm{d}} \text { we arrive at: } \\
& Z_{1}^{\backslash d}=\quad A\left[\Delta^{\backslash d}-\delta^{d} \mathbb{I}\right]^{\mathrm{T}}\left\{\left[\Delta^{\backslash \mathrm{d}}-\delta^{\mathrm{d}} \mathbb{I}\right]\left[\Delta^{\backslash \mathrm{d}}-\delta^{\mathrm{d}} \mathbb{I}\right]^{\mathrm{T}}\right\}^{-1}
\end{aligned}
$$

that is to say $z_{1}^{i} \in\langle A\rangle, \quad i \neq d$.

Since $z_{1}^{d}\left(*^{*}\right)=-\sum_{i \neq d} z_{1}^{i}(\stackrel{*}{\pi})$, from this it also follows that $z_{1}^{d} \in\langle A\rangle$, and we obtain that $z_{1}^{i}(*) \in\langle A\rangle, \quad i=1, \ldots, I$.

Note that, generically in $\delta_{k}^{i}, \operatorname{rg}\left[\triangle^{\backslash d}-\delta^{d} \mathbb{I}\right]=\mathrm{I}-1$ provided $K \geq I-1$. Hence a sufficient assumption to obtain both belief connectedness and full rank is $K \geq I-1$ provided consumers' initial shares are chosen from some generic subset of the set of all positive $K \times K$ matrices..

For an intuition of this claim reconsider Example 1 once again. In the case where $\delta^{1}=\delta^{2}=\frac{1}{2}$, the economy is belief connected, $\operatorname{rg}(\triangle)=I-1$ but still equilibria are not Pareto-efficient because then $\stackrel{*}{a}=\delta^{1} z_{1}^{1}(\stackrel{*}{\pi})+\delta^{2} z_{1}^{2}(\stackrel{*}{\pi})=\frac{1}{2}\left(z_{1}^{1}(\stackrel{*}{\pi})+z_{1}^{2}(\stackrel{*}{\pi})\right)=0$. This choice of initial shares violates the rank condition rank $\left[\triangle^{\backslash d}-\delta^{d} \mathbb{I}\right]=\mathrm{I}-1$ because in this case $\left[\triangle^{\backslash d}-\delta^{d} \mathbb{I}\right]=\left(1-2 \delta^{d}\right)$ which is 0 for both agents $d=1$, 2. However, this choice is clearly exceptional and as mentioned above any other choice would lead to full Pareto-efficiency because $\stackrel{*}{a}=\left(1-2 \delta^{1}\right) z_{1}^{1}(\stackrel{*}{\pi})$.

For an interpretation of Theorem 4 note that in our Example 2 with I firms using an active financial policy the communication of beliefs selects the Pareto-efficient equilibrium. Hence in this setting efficient financial innovation can be seen as a coordination problem (Citanna and Villanacci (1996)) which we solve by introducing communication.

\section{Remark 1:}

In the proofs of the Theorems 3 and 4 it was shown that under the assumptions stated the allocation of stock market equilibria with financial policy and communication coincide with equilibrium allocations of the corresponding complete markets ArrowDebreu economy. Hence under those assumptions the existence of stock market equilibria with relevant financial policy and communication follows from standard arguments given in the Arrow-Debreu model (Debreu (1959)).

\section{Remark 2:}

It should be obvious from the proofs of Theorem 3 and 4 that these results extend straightforwardly to the case of multiple commodities. In Theorem 3 stock markets are complete and in Theorem 4 by the financial policy of the firm all the net transfers of income can be generated by trading on asset markets. 


\section{Remark 3:}

Finally note that the assumptions of Theorem 3 and Theorem 4 are tight in the sense that if the number of firms is relatively small as compared to the number of states and to the number of consumers then Pareto-efficiency cannot be expected. Suppose the number of states $\mathrm{S}$ is large enough so that those components of the complete markets equilibrium excess demand

$$
\begin{aligned}
z^{i}(\pi)=\quad & \arg \max _{z^{i}} U^{i}\left(\omega^{i}+\sum_{k} \delta_{k}^{i} \stackrel{*}{*}^{k}+z^{i}\right) \\
& \text { s.t. } * * z^{i} \leq 0 \text { and } \\
& \left(\omega^{i}+\sum_{k} \delta_{k}^{i} y^{*}+z^{i}\right) \in \mathcal{X}^{i}
\end{aligned}
$$

which are not spanned by $\left\langle Y_{1}^{*}\right\rangle$ are still heterogeneous enough to span a space of dimension larger than K. Then the financial policy will not suffice to guarantee Pareto-efficiency, as can be seen from a revised version of Example 1.

\section{Conclusion}

When markets are incomplete the firm's production decision has two effects on consumers: it changes the market value of their shares and it changes their risk sharing opportunities. To disentangle these two conflicting objectives we allow the firm to choose some active financial policy, i.e. to issue assets for which the production plan is used as collateral.

We assume that consumers hold beliefs about the profitability of alternative production plans. Depending on the degree of heterogeneity of beliefs the resulting equilibria can be Pareto-efficient or Pareto-inefficient. The question of Pareto-efficiency then becomes a coordination problem which we solve by communication of beliefs. Our main results show that stock market equilibria with active financial policy and communication are Pareto-efficient provided there are at least as many firms as there are consumers.

Although the results presented in this paper show that constrained inefficiency of stock market equilibria can be removed by introducing relevant financial policies and communication, there still are a number of important open issues.

\section{Open issue 1 (Constrained Pareto-efficiency with an insufficient number of financial innovations):}

If there are less than $(I-1)$ linearly independent financial innovations, then the production decision of the firm again becomes relevant as a financial asset, and hence, Pareto-efficiency of the equilibrium might go away if markets are incomplete. The question now is whether the resulting equilibrium allocation will at least be constrained Pareto-optimal. In particular, if firms are unproductive, one could study whether a planner who could choose $K$ degrees of freedom in the space of potential 
net-trades, $\mathbb{R}^{S}$, could improve on the equilibrium allocation ${ }^{14}$

\section{Open issue 2 (Generalization of Example 1):}

It is not clear whether Example 1 can be generalized to a theorem of the following kind: Suppose that $K<S$ and that the production decisions are not significant compared to the endowments available to the economy ( $\varepsilon$ small in Example 1$)^{15}$ Let $\stackrel{*}{y}$ be the optimal solution chosen by the social planner. Then there is no set of state prices $\stackrel{*}{\pi}$ such that $\stackrel{*}{y}$ is profit maximal with respect to $\stackrel{*}{\pi}$ for all firms $k=1, K$.

\section{Open issue 3 (Dynamic foundation of equilibrium concept):}

The equilibrium concepts studied in this paper are pure fixed point concepts, where an auctioneering process leading to these equilibria is not specifically modelled. Since assets are partly endogenous in this model, namely the shares of the firm whose payoffs are determined by the production decision of the firm, it is not at all how obvious how the standard dynamic foundation given for the case of an exchange economy (for a general review see Hahn (1982)) could be extended to this case. Principally, a dynamic process supporting a stock market equilibrium could work like this: Start e.g. with assuming that the individuals hold some exogenous beliefs about the true state prices. Based on these beliefs, the firms suggest some production plan contained in the production set and satisfying the profit maximization criterion. Then the auctioneer announces a set of asset prices, both for the exogenous assets and for the shares of the firms. Based on these asset prices, consumers check whether their beliefs are consistent with the no arbitrage-conditions. If they are not consistent, beliefs and, consequently, production plans need to be updated, and the sequence of events is repeated. If the shareholders, however, agree to the production plans suggested, then the consumers announce their net-trading plans at the given asset prices. If markets clear, an equilibrium is found. Otherwise, the auctioneer will announce new asset prices, at which shareholders need to reevaluate the production plans, and consumers eventually recompute their asset demands.

\section{References}

[1] Allen, F. And D. Gale (1994), "Financial Innovation and Risk Sharing", MIT-Press, Cambridge MA.

[2] Bisin, A. (1998), "General Equilibrium Economies with Imperfectly Competitive Financial Intermediaries", Journal of Economic Theory 82 (1), 19-45.

\footnotetext{
${ }^{14}$ Consider e.g. a version of example 1 , where $S=4$ and $I=3$ with similar symmetry properties. Then the rank condition of Theorem 4 would not be satisfied. In general, the asset which would be innovated would not lie within the span of desired complete markets net-trades, but some level of risk-sharing would be achieved. Whether this level is sufficient to yield a constrained Pareto-efficient allocation remains an unsolved question.

${ }^{15} \mathrm{It}$ is a particularly interesting question how the apparent trade- off between risk-sharing $(\varepsilon$ small) and production ( $\varepsilon$ large) can be formalized in more general settings.
} 
[3] Citanna, A. And A. Villanacci (1996), "Financial Innovation", Penn Working Paper.

[4] Debreu, G. (1959), "Theory of Value", Wiley Mew York.

[5] De Marzo, P. (1988), "An Extension of the Modigliani Miller Theorem to Stochastic Economies with Incomplete Markets", Journal of Economic Theory 45, pp. 353-369.

[6] De Marzo, P (1993), "Majority Voting and Corporate Control: The Role of the Dominant Shareholder", Review of Economic Studies 60 (3), July '93, pp. 713-34.

[7] De Marzo, P., Vayanos, S. ans J. Zwiebel (1997), "A Near-Rational Model of Persuasion with Implications for Financial Markets", Stanford University, mimeo.

[8] Dierker, E., Dierker, H. And B. Grodal (1999), "Incomplete Markets and the Firm", University of Vienna, mimeo.

[9] DrÈze, J. (1974), "Investment under Private Ownership: Optimality, Equilibrium and Stability", in: Allocation under Uncertainty: Equilibrium and Optimality, J.H. Drèze ed. New York: Wiley, 129-165.

[10] Dubey, P., Geanakoplos, J., Shubik, M. (1997), "Default and Efficiency in a General Equilibrium Model with Incomplete Markets", Cowles Foundation, Yale University, mimeo.

[11] Duffie, D. And R. RAhi (1995), "Financial Market Innovation and Security Design", Journal of Economic Theory Symposium on Financial Innovation and Security Design, Vol. 65 (1), pp. 1-42

[12] Duffie, D. And W. Shafer (1988), "Equilibrium and the role of the firm in incomplete markets", GSB working paper No. 915, Stanford University.

[13] Geanakoplos, J. (1990), "An Introduction to General Equilibrium with Incomplete Asset Markets", Journal of Mathematical Economics 19, pp. 1-38.

[14] Geanakoplos, J. and H. Polemarchakis (1986), "Existence, regularity and constrained suboptimality of competitive allocations when markets are incomplete", in: W.P. Heller, R.M. Ross and D.A. Starrett (eds.), "Uncertainty, information and communication", Essays in honor of Kenneth Arrow, Vol. 3, Cambridge: Cambridge University Press.

[15] Geanakoplos, J., Magill, M., Quinzis, M., Drèze, J. (1990), "Generic Inefficiency of Stock Market Equilibrium when Markets are Incomplete", Journal of Mathematical Economics, 19, pp. 113-152.

[16] Grossman, S. And O. Hart (1979) "A Theory of Competitive Equilibrium in Stock Market Economies", Econometrica 47, pp. 293-330. 
[17] Guesnerie, R. (1975), "Pareto-Optimality in Non-convex Economies" Econometrica 43, pp. 1-31.

[18] Hahn, F. (1982), "Stability" Chapter 16 in: Handbook of Mathematical Economics, vol. II, K. Arrow and M. Intriligator (eds,), Amsterdam: NorthHolland.

[19] Hens, Тн. (1998), "Incomplete Markets", Chapter 5 in: Elements of General Equilibrium Theory, Festschrift in Honor of G. Debreu, A. Kirman (ed.), Blackwell Publishers.

[20] Kemeny And Snell (1976), "Markov Chains", Springer.

[21] Magill, M. And M. Quinzir (1996), "Theory of Incomplete Markets: Vol I", MIT-Press, Cambridge MA.

[22] Magill, M. And W. Shafer (1991), "Incomplete Markets", in: Handbook of Mathematical Economies, Vol. 4 .

[23] Matsui (1991), "Cheap talk and cooperation in society", JET (54), pp. 24558 .

[24] Murata, Y. (1977), "Mathematics for Stability and Optimization of Economic Systems", Academic Press: New York.

[25] UEKawA, Y. (1971), "Generalization of the Stolper-Samuelson-Theorem", Econometrica (39), pp. 19\%-21\%.

[26] ZAme, W. (1993), "Efficiency and the Role of Default when Security Markets are Incomplete", American Economic Review 83, 1142-1164. 